\title{
The American School of Oboe Playing: Robert Bloom, John de Lancie, John Mack, and the Influence of Marcel Tabuteau
}

Amy M. Galbraith

West Virginia University

Follow this and additional works at: https://researchrepository.wvu.edu/etd

\section{Recommended Citation}

Galbraith, Amy M., "The American School of Oboe Playing: Robert Bloom, John de Lancie, John Mack, and the Influence of Marcel Tabuteau" (2011). Graduate Theses, Dissertations, and Problem Reports. 3541.

https://researchrepository.wvu.edu/etd/3541

This Dissertation is protected by copyright and/or related rights. It has been brought to you by the The Research Repository @ WVU with permission from the rights-holder(s). You are free to use this Dissertation in any way that is permitted by the copyright and related rights legislation that applies to your use. For other uses you must obtain permission from the rights-holder(s) directly, unless additional rights are indicated by a Creative Commons license in the record and/ or on the work itself. This Dissertation has been accepted for inclusion in WVU Graduate Theses, Dissertations, and Problem Reports collection by an authorized administrator of The Research Repository @ WVU.

For more information, please contact researchrepository@mail.wvu.edu. 
The American School of Oboe Playing:

Robert Bloom, John de Lancie, John Mack, and the

Influence of Marcel Tabuteau

\author{
Amy M. Galbraith \\ Doctoral Research Project submitted to the \\ College of Creative Arts \\ at West Virginia University \\ in partial fulfillment of the requirements \\ for the degree of
}

Doctor of Musical Arts in Oboe Performance

\author{
Cynthia Anderson, M.M., Chair \\ John Weigand, D.M.A. \\ Andrew Kohn, Ph.D. \\ Lynn Hileman, D.M.A. \\ Alison Helm, M.F.A.
}

Division of Music

Morgantown, WV

2011

Keywords: Oboe, American School, Bloom, de Lancie, Mack, Tabuteau, Reed Making

Copyright 2011 Amy M. Galbraith 


\section{ABSTRACT \\ The American School of Oboe Playing: \\ Robert Bloom, John de Lancie, John Mack, and the \\ Influence of Marcel Tabuteau}

Amy M. Galbraith

The American school of oboe playing is a distinct national style that evolved during the twentieth century. It is characterized by a darker tone than other national schools and a phrasing style that emphasizes long, connected lines with nuances in tonal intensity. The style was developed by Marcel Tabuteau, and is distinguished by his modified "long scrape" reed as well as the numerical system he used to teach musical phrasing. Even today, his ideas continue to disseminate, and most American oboists can trace their pedagogical roots back to Tabuteau. Yet despite the school's evolution from one person, diversity exists. This project researches three of Tabuteau students: Robert Bloom, John de Lancie, and John Mack, chosen for their influence as both performers and as pedagogues, and the focus of the research is on their approach to tone production and musicianship. Because reed making is interconnected with tone production, reed styles are also compared. Research reveals that variations exist within the American school; however from a global perspective, the similarities still suggest a unified style. 


\section{ACKNOWLEDGEMENTS}

I am indebted to Dr. John Weigand for his help in completing this research project. I cannot adequately express my gratitude toward his continued support and friendship. I also wish to thank my mentor, Cynthia Anderson for her guidance over the years, and Dr. Lynn Hilemann for her detailed and insightful advice, which greatly improved my writing skills. Thank-you also to Dr. Andrew Kohn for his helpful comments, and for his interesting analysis classes. Finally, to Allison Helm for opening my eyes to the perspectives of other artistic disciplines.

On a personal level, I need to express my appreciation toward my family and close friends for their continued love and support. Especially to Dr. James Ogburn, my fiancé and editor-in-chief, who was by my side throughout this process, and to my parents, Nancy and Matthew Galbraith. Thank you also to my loving sister, Dr. Sarah Bond and her beautiful family, Jeremy, Gabrielle, and Madeline. Also, I am grateful for the support of my aunt and uncle, Ron and Joan Giles, and my pastors, George and Caroline Mendis. Finally, thank you to Dr. Sugree Charoensook, the Dean of the College of Music at Mahidol University, who continues to inspire me with his tireless energy and positive vision. 


\section{Table of Contents}

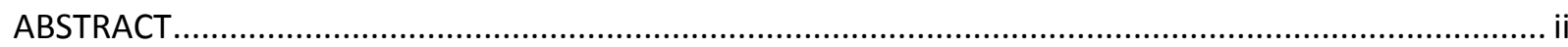

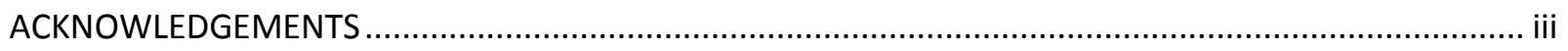

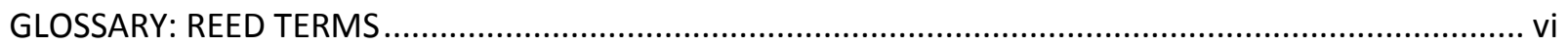

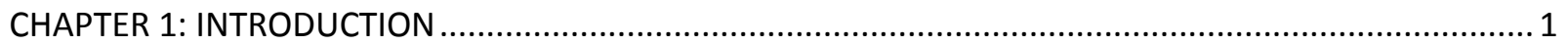

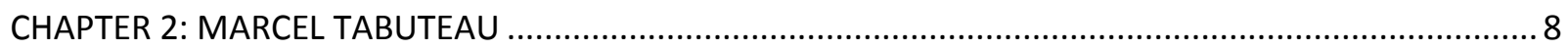

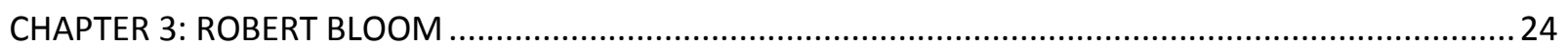

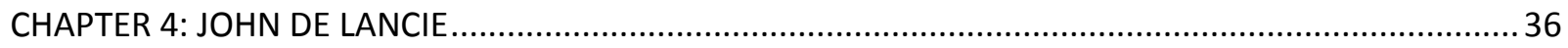

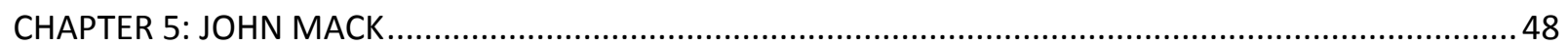

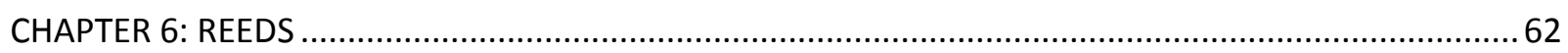

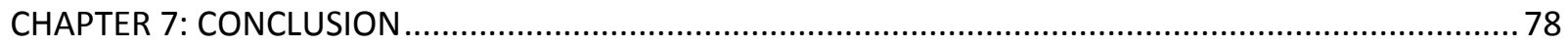

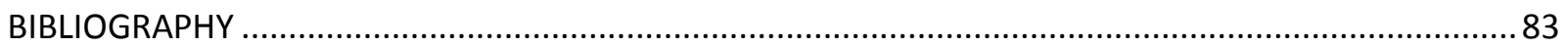

Appendix A: Prominent Students of Marcel Tabuteau at the Curtis Institute of Music.........................87

Appendix B: Reed Dimensions of Select American Style Oboists ................................................... 88 


\section{List of Tables and Figures}

Figure 1. Diagram of the "American" (long scrape) and "European" (short scrape) Reed Styles:........... vii

Figure 2. Note Grouping illustrated in "Sakura" from Madame Butterfly .............................................. 16

Figure 3. Distribution illustrated in "Sakura" from Madame Butterfly ................................................ 17

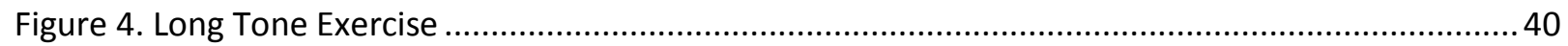

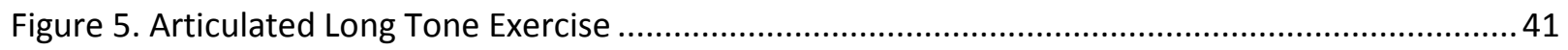

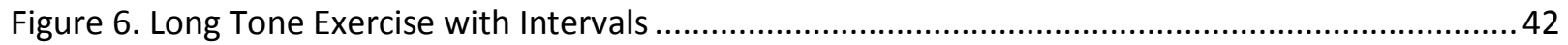

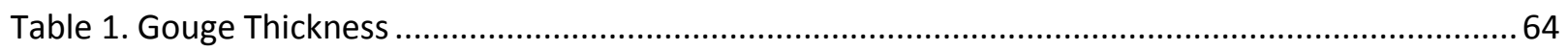

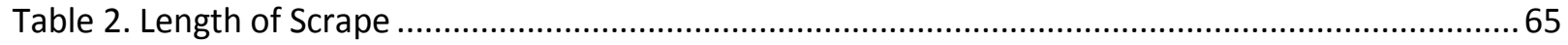

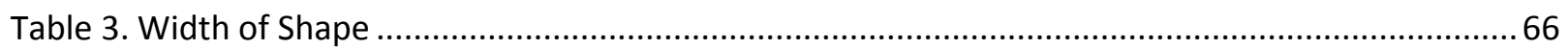

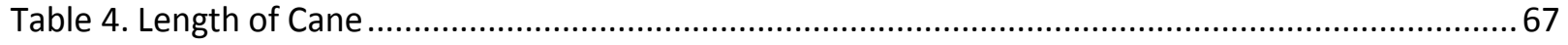

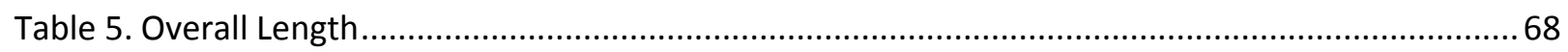

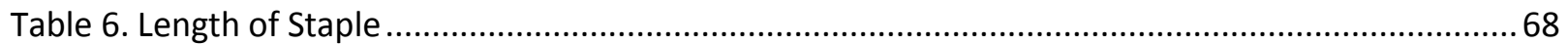

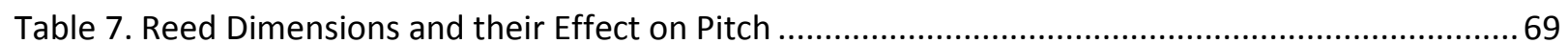




\section{GLOSSARY: REED TERMS}

Cane (Arundo Donax): Largest species of grass. This plant is used to make reeds for oboe, clarinet, saxophone, and bassoon players. Cane grows in tubes, which are cut to 4-8 inch lengths to make reeds. Although it is indigenous to sub-tropical climates, most musicians use cane grown in the Var region of France. Sometimes oboists refer to the cane as "wood." For example, one scrapes wood (cane) off the reed to make it vibrate more easily when played.

Bark: Bark is the outermost layer of a piece of cane. Shiny in appearance, reed makers leave varying amounts of bark on the reed, depending on the style of reed.

Gouge: The gouge refers to the measurement of the thickness of cane after the tube cane has been cut into thirds, and the single piece has been shaved thin using a planer. The thickness of the gouge, as well as the relative proportions between the center and the sides of the cane, affects the tone quality of the finished reed.

Shape: Shaping the cane is the last stage of preparation before the cane can be made into a reed. The piece of cane is folded into two halves and tapered using a mold, known as the shaper tip. The curve and width of the shape directly affect the tone quality and pitch of the finished reed. Different reed styles dictate the shape that a reed maker chooses.

Staple: A metal tube made of brass or silver that the cane is tied upon. The staple is essentially an extension of the bore of the oboe. Part of the tube is covered with cork, which allows the tube to fit into the opening of the top of the oboe. The most common length used by oboists is 47 millimeters.

Binding: The piece of shaped cane is tied onto the staple using nylon or silk thread.

Scrape: The act of scraping the reed involves shaving the bark off of the reed in varying degrees in order for the reed to vibrate when the player blows through the opening. A reed where the bark has only been shaved to the half-way point or less between the opening and the binding is defined as a "short scrape" reed. This scrape is common among European styles. A "long scrape" reed is a reed in which the bark has been removed until approximately four millimeters above the binding. This scrape evolved in America through Marcel Tabuteau and his students.

\section{Parts of the "American Style" Reed:}

1. Tip: The thinnest part of the reed. The tip of the reed is where the opening is located. The tip is scraped thinner on the sides and corners and left thicker in the center. This contour creates a darker tone quality. The back corners of the tip are also scraped thin, so the design resembles an "inverted V" shape.

2. Lay: (also called the hump, slope, or blend) The lay is the transitional area between the tip and the heart of the reed. The thickness and degree of slope in this "blend" 
area affects the resistance and stability of the reed. In a short scrape reed, the lay often contains the heart.

3. Heart: (also called the plateau) The heart is the thickest part of the reed. Following the natural curvature of the gouge, this area is also scraped thinner on the sides than in the middle. The amount of cane left in the heart of the reed affects the resistance, tone quality, and opening of the reed.

4. Back: The back of the reed is the rest of the scraped area between the heart and the binding. The back of the reed contains the "windows". The windows are the second thinnest area of the reed. They help lower the overall resistance of the reed so that the heart can be thicker, which creates a richer tone quality. The windows also help to stabilize the upper register.

Figure 1. Diagram of the "American" (long scrape) and "European" (short scrape) Reed Styles:

American

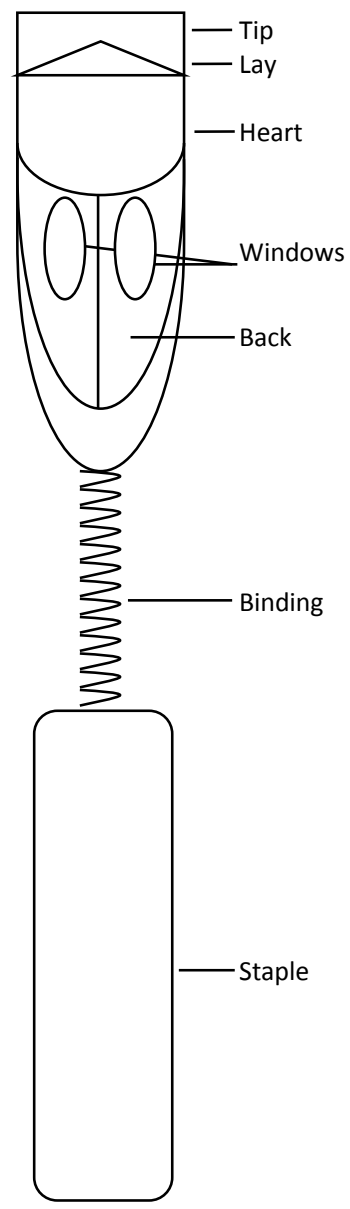

European

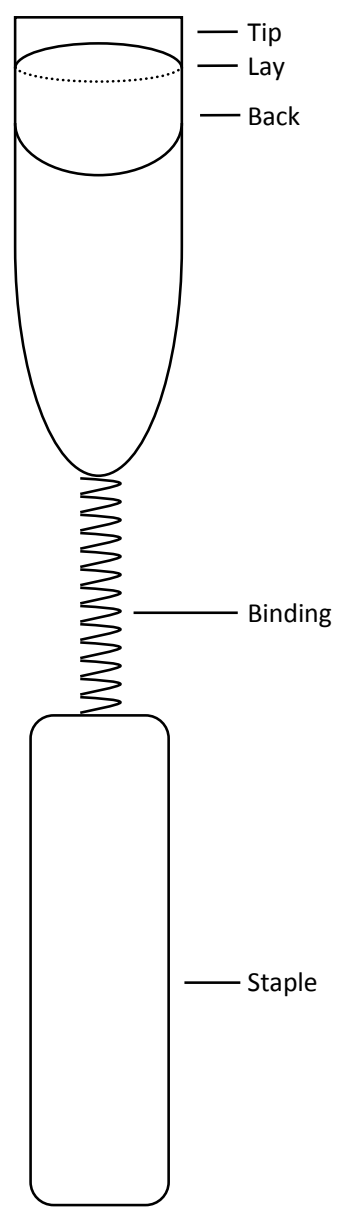




\section{CHAPTER 1: INTRODUCTION}

The American school of oboe playing is a distinct national style that evolved during the twentieth century. "Although it has been heavily influenced by various European styles of playing," Lana Neal describes the American style as "a unique school characterized most importantly by an emphasis on the production of what can be best described as a rich, dark tone and on a management of phrasing that emphasizes the smoothness and continuity of melodic lines." ${ }^{\prime \prime}$ The characteristic tone and the flexibility required to produce the desired phrasing is facilitated by the "long" reed scrape used by the American school.

Marcel Tabuteau, principal oboist of the Philadelphia Orchestra from 1915 until 1954, is often referred to as the founder of the American style of oboe playing. ${ }^{2}$ Prior to immigrating to the United States in 1905 to play for the New York Symphony, Tabuteau received his musical training at the Paris Conservatory where he studied with renowned French oboist Georges Gillet (1854-1920).

Tabuteau's playing style evolved throughout his career, particularly during his tenure with the Philadelphia Orchestra. Leopold Stokowski's relentless demands for a varied, wide range of tone color and for individual wind instruments to blend as a section caused Tabuteau to modify the characteristic oboe tone associated with the French school. Oboists of the French school constructed their reeds in a way that emphasized the upper partials in the tone. By lengthening the traditional French reed scrape, Tabuteau was able to add lower partials to the tone. The result was a significant change in tone quality, and the genesis of a distinct style of reed making that is different from other national styles.

\footnotetext{
${ }^{1}$ Lana C. Neal, "The American School: Its History and Hallmarks," The Double Reed 22 (1999): 51.

${ }^{2}$ Ibid.
} 
Throughout his long performance career, Tabuteau was praised for his phrasing style that involved long, connected lines and nuances of inflection. As a pedagogue, he developed a system that allowed him to clearly communicate his phrasing ideas. Rooted in music theory, his phrasing was based upon the analysis of note groupings and the idea that music is always in motion. Tabuteau referred to "ups and downs" in direction, and his system incorporated numbers to reflect not only graduations in dynamics, but also intensity and variations of tone color. So, in addition to making modifications of tone quality and reed style, Tabuteau is distinguished for his phrasing system.

Because of the effectiveness of his system, Tabuteau's significance lies not only in his abilities as a performer, but also as a pedagogue. During his long teaching career at the Curtis Institute of Music, he produced students who came to occupy oboe positions in the top orchestras and conservatories throughout the country. In the generations that followed, Tabuteau students became the leading performers and pedagogues in the United States. Most oboists trained in America can trace their pedagogical roots back to Tabuteau.

The emphasis of Tabuteau's teaching was on phrasing and musical interpretation. Yet, while his students presumably received similar training to each other, there are differences among their own styles. These differences are significant enough that some scholars argue against the notion of one unified American school of oboe playing. According to Geoffrey Burgess,

Of all schools, arguably, the existence of a homogenous American style is hardest to justify. The differences separating the playing of...the best-known figures of the American school past and present seem to outweigh the similarities. Nevertheless, all... are bound by an allegiance to the American oboe school. Indeed, it is perhaps precisely because of its considerable internal variation that the American school has been ideologically the strongest. It was the first to establish a national organization- the 
International Double Reed Society-which through its publications has documented the history of the oboe in the USA. ${ }^{3}$

While much scholarly attention has been devoted to Marcel Tabuteau and the history of the American school, there lacks a body of research that identifies evolutionary changes since Tabuteau. This research project examines the pedagogy of three of Tabuteau's most prominent students: Robert Bloom (1908-94; Bach Aria Group 1946-80), John de Lancie (1921-2002; Philadelphia Orchestra 1946-77), and John Mack (1927-2006; Cleveland Orchestra 1965-2001) in order to discover how each developed his own approach to teaching tone production and reed making to facilitate the desired melodic phrasing in his students. Tone production involves such topics as embouchure formation, air support, dynamics, color changes, articulation, and vibrato, all of which relate to how the player performs the musical line. This research includes ways these players communicated their ideas to their own students. Because tone production is interconnected with individual reed style and construction, this study also incorporates a comparison of reed styles. Though none of these oboists are alive today, many of their students are currently the most influential players in the country. Because of the broad scope of this topic, research was limited to Bloom, de Lancie, and Mack, who were chosen because of the impact they, as well as their students, have had on the contemporary American school of oboe playing. This research is valuable because it will show how the American school has evolved since Tabuteau.

The procedure for this project involved researching the available literature pertaining to the topic and drawing conclusions based on that information. Notable resources include

\footnotetext{
${ }^{3}$ Geoffrey Burgess and Bruce Haynes, The Oboe (New Haven: Yale University Press, 2004), 205. It should be noted that the IDRS was formed in collaboration with bassoonists.
} 
numerous articles published in the journal for the International Double Reed Society ${ }^{4}$, interviews, pedagogical recordings, masterclasses, and books. Fortunately there are primary sources from Bloom, de Lancie, and Mack that proved invaluable for this research. Marcel Tabuteau's Lessons $^{5}$ is a recording that Wayne Rapier, former oboist of the Boston Symphony and Tabuteau student, produced from approximately five hours of tapes that Tabuteau made in $1965-66 .{ }^{6}$ The liner notes present a transcription of his lessons. Sara Bloom published a vast biography of Robert Bloom, Robert Bloom: The Story of a Working Musician ${ }^{7}$, which includes his treatise on pedagogy, The Oboe, A Musical Instrument. John Mack's article, "Effective Guidance for the Young Oboist," is notable because he discussed his ideas concerning tone quality, breathing, embouchure, articulation, and reed making. ${ }^{8}$ Additionally, Mack’s recording Orchestral Excerpts for the Oboe contains his comments on how to perform the chosen excerpts in order to create the proper musical expression. ${ }^{9}$ Listening to this recording is a unique opportunity to hear Mack's coaching directly. "Marcel Tabuteau: Pedagogical Concepts and Practices for Teaching Musical Expressiveness: An Oral Tradition (Oboe)" by Melissa Stevens is a research project in which she recorded Tabuteau's concepts and teaching practices concerning musical expression by interviewing several students of Tabuteau, including John Mack and John de Lancie. ${ }^{10}$ These interviews offer biographical information, discussions of the Tabuteau "number system," and descriptions of his personality and teaching style.

\footnotetext{
${ }^{4}$ The journal publications for the International Double Reed society have undergone some changes since the society's inception. Prior to 1978, the society published The Double Reed, To the World's Bassoonists, and To the World's Oboists. From 1973-1999, the society simultaneously published The Journal of the International Double Reed Society and The Double Reed. Currently, one journal, The Double Reed is published four times per year. ${ }^{5}$ Marcel Tabuteau, Marcel Tabuteau Lessons, Boston Records, BR1017CD, 1996.

${ }^{6}$ Rapier, Wayne, "Marcel Tabuteau Tape History," Marcel Tabuteau Lessons, Boston Records, BR1017CD, 1996.

${ }^{7}$ Sara Lambert Bloom, Robert Bloom: The Story of a Working Musician. (United States: Sara Lambert Bloom, 2009).

${ }^{8}$ John Mack, "Effective Guidance for the Young Oboist," Journal of the International Double Reed Society2 (1974).

9 John Mack, Orchestral Excerpts for the Oboe, Summit Records, Orchestral Pro Series DCD 160, 1994.

${ }^{10}$ Melissa Stevens, "Marcel Tabuteau: Pedagogical Concepts and Practices for Teaching Musical Expressiveness: An Oral Tradition (Oboe),” D.M.A. diss., The Ohio State University, 1999.
} 
In addition to primary sources, materials provided by students of Tabuteau, Bloom, de Lancie, and Mack also proved useful for this research. Students offer insight into their teachers' ideas because their thoughts often reflect those of their teachers'. This assumption is most evident in the chapter on de Lancie (Chapter 4), for several of his students have published works that reflect his teaching. For example, Marilyn Zupnick's recording A Guide to Classic Oboe Etudes $^{11}$ supplies her performance of and commentary on Barret, Brod, and Ferling etudes. Barret, Brod, and Ferling were all oboists, and their etudes have continued to shape the development of players since the nineteenth century. Another example is Jay Light's Essays for Oboists, which contains Light's thoughts on embouchure formation, vibrato, breathing and air support, articulation, and note groupings and includes musical examples taken from the solo repertoire and the Barret etudes with his remarks on how to perform these pieces. ${ }^{12}$ Light also published The Oboe Reed Book..$^{13}$ This book and David Weber's The Reed Maker's Video impart valuable wisdom concerning the American reed style, as they learned through de Lancie. ${ }^{14}$ Martin Schuring's Oboe Art and Method is a helpful source for detailed information on the fundamental aspects of tone production as well as musical phrasing, which is influenced by his studies with de Lancie. ${ }^{15}$

Lastly, there are several sources that offer additional information into the American school. Lana Neal's article, "The American School: Its History and Hallmarks" gives significant background information for understanding and defining the American school. Laila Storch, Tabuteau's main biographer and former student, published a memoir entitled Marcel Tabuteau:

\footnotetext{
${ }^{11}$ Marylin Zupnick, A Complete Guide to Classic Oboe Etudes, DLM Records 0688-CD-0049, 1998.

${ }^{12}$ Jay Light, Essays for Oboists (Des Moines, IA: Jay Light, 1994).

${ }^{13}$ Jay Light, The Oboe Reed Book: Straight-Talking Guide to Making and Understanding Oboe Reeds, (Des Moines, IA: Jay Light, 1983).

${ }^{14}$ David B. Weber and Ferald B. Capps, The Reed Maker's Video, RMV-DVD-R.

${ }^{15}$ Martin Schuring, Oboe Art and Method (New York: Oxford University Press, 2009).
} 
How Do You Expect to Play the Oboe if You Can't Peel a Mushroom, which provided a large amount of background information on Tabuteau and his students. ${ }^{16}$ Sound in Motion: A Performer's Guide to Greater Musical Expression by bassoonist David McGill was helpful in explaining the "Tabuteau system," especially in terms of its continued use through de Lancie at the Curtis Institute. ${ }^{17}$

This paper begins with a chapter devoted to Marcel Tabuteau and the evolution of the American school from his pedagogy and performance practices. Following this chapter, Bloom, de Lancie, and Mack are each given a chapter in which the focus is on his career and approach to teaching tone production. Finally, the last chapter is a study of the reeds of Tabuteau, Bloom, Mack, and some of their students, based on the data provided by David Ledet's Oboe Reed Styles: Theory and Practice. ${ }^{18}$ Ledet provided objective, statistical data that was useful for studying the similarities and differences among reeds of select American school oboists. ${ }^{19}$ Because of the various reed-making terms used among oboists but perhaps not familiar to other readers, a glossary and reed diagram has been provided in the front matter of the paper (pages vii-viii).

The American school of oboe playing has evolved since its origin. As this paper will demonstrate, the school has diversified despite the fact that the prominent players of today can trace their lineage back to a single influence, Marcel Tabuteau. The research for this project draws conclusions as to why the tone of American oboists today varies so greatly within a general style. While a number of resources exist that are pertinent to this research, none deals

\footnotetext{
${ }^{16}$ Laila Storch, Marcel Tabuteau: How Do You Expect to Play the Oboe if You Can't Peal a Mushroom? (Bloomington and Indianapolis: Indiana University Press, 2008).

${ }^{17}$ David McGill, Sound in Motion: A Performer's Guide to Greater Musical Expression (Bloomington: Indiana University Press, 2007).

${ }^{18}$ David A. Ledet, Oboe Reed Styles: Theory and Practice (Bloomington: Indiana University Press, 1981).

${ }^{19}$ This chapter is focused on the information found in Ledet's study because of its objective, scientific method for analyzing reed styles. De Lancie did not provide reeds for Ledet's study, but reeds of his students have been included for this project.
} 
directly with this topic. The extant material describes the foundation of the American school as it is relevant to playing today. These resources were utilized to draw conclusions about the individual ways Bloom, de Lancie, and Mack approached tone production, reed making, and musical phrasing. These conclusions illuminate the similarities and differences within the current American school of oboe playing. 


\section{CHAPTER 2: MARCEL TABUTEAU}

Marcel Tabuteau (1887-1966) grew up in Compiègne, a small town north of Paris. At age six, he began his musical training with his brother-in-law, Émile Létoffé, who taught young Tabuteau to play the violin and trained him in solfège. He switched to oboe when the local town band, the Harmonie Municipale, recruited him out of a need for wind players. $^{20}$

Tabuteau demonstrated a special talent for the oboe and began taking lessons with Georges Gillet (1854-1920) in Paris. $^{21}$ Gillet is credited with firmly establishing the distinguished French school of oboe playing through his long tenure (1881-1919) at the Paris Conservatoire. $^{22} \mathrm{He}$ progressed rapidly with Gillet and in the fall of 1902, at age fifteen, Tabuteau auditioned for and was accepted into Gillet's class at the Paris Conservatoire. At the Conservatoire, he was an exceptional student and was awarded the esteemed Premier Prix after only two years of study. ${ }^{23}$

Gillet had a significant impact upon Tabuteau, who often gave credit to his teacher for "everything he knew about music and the oboe" and claimed that "Gillet was the greatest musician I have ever known." ${ }^{24}$ As Laila Storch states in her biography of Tabuteau,

The single most admired aspect of Tabuteau's playing was always his phrasing; it was on a level not ordinarily encountered in the era when simply a pleasant sound and adequate finger facility were sufficient to secure an oboist's career. Whatever work Tabuteau played, one had the feeling of hearing its essence distilled into three or four measures of the oboe line. His complete control of the wind, which he used to express every nuance, was based on his lifetime dedication to the principles first pointed out to him by Georges Gillet. $^{25}$

\footnotetext{
${ }^{20}$ Laila Storch, Marcel Tabuteau, 7-8.

${ }^{21}$ Laila Storch, liner notes, Marcel Tabuteau Lessons, CD, Boston Records, 1996.

${ }^{22}$ Storch, Marcel Tabuteau, 23.

${ }^{23}$ Storch, liner notes.

${ }^{24}$ Storch, Marcel Tabuteau, 21.

25 Ibid., 22.
} 


\section{ORCHESTRAL CAREER}

In the first decades of the twentieth century, American orchestras were few in number and still in the early stages of development. In addition, a pedagogical musical tradition for the training of professional orchestral players was not yet established. Consequently conductors recruited recent graduates from European conservatories, with the result that many outstanding musicians emigrated from Europe to play in American orchestras. ${ }^{26}$

American orchestras of this era were dominated by German musicians. In fact, Germans were also the principal patrons of the orchestras. ${ }^{27}$ However, the French school of woodwind playing was gaining worldwide recognition and Paris Conservatoire graduates were "in high demand." ${ }^{28}$ Gillet's students were earning prominent positions in both American and French orchestras. For example, the Boston Symphony Orchestra hired Georges Longy in 1898 and, in 1903, Alfred Barthel joined the Chicago Symphony Orchestra.

In 1905, Tabuteau began his career as an oboist after the conductor Walter Damrosch recruited him to play English horn in the New York Symphony Orchestra. Tabuteau was among the "famous five" French wind players who were all recruited at the same time and gained moderate celebrity. The five included Georges Barrère, flute; Lèon Leroy, clarinet; Marcel Tabuteau, oboe and English horn; Adolphe Dubois, trumpet; and Auguste Mesnard, bassoon. Tabuteau, who was recommended to Damrosch by Gillet, was the youngest of the five; the rest had "considerable solo and orchestral experience."29

Although Damrosch ran into problems with the union, this importation of French players proved to be successful and, within the first few months of their arrival, the orchestra's new wind

\footnotetext{
${ }^{26}$ David McGill, Sound in Motion, 4-5.

${ }^{27}$ Storch, Marcel Tabuteau, 40.

28 Ibid.

${ }^{29}$ Ibid.
} 
players were already gaining positive critical reviews. Note this New York Times review of the opening concert on November 14, 1905:

The wind instrument players who were brought over from Paris by Mr. Damrosch last summer, and who were heard at that time in the popular concerts, have very materially strengthened [the orchestra], and the woodwind choir can offer a beauty of tone and a finish of execution such as have not been heard from resident players for a long time...The tone of the orchestra is good, homogeneous, and in the main well balanced, and much of the roughness that characterized its playing last season has been refined away. $^{30}$

After three seasons with the New York Symphony Orchestra, Tabuteau became the principal oboist of the Metropolitan Opera Orchestra, a position he maintained for several seasons. Fortunately for Tabuteau, he entered the orchestra during one of its most productive and successful periods. With the Met, he played under conductors Arturo Toscanini and Gustav Mahler along with exceptional instrumentalists from Russia, France, and Germany. Known as the "Golden Age" of renowned vocalists, during this period the Met performed many demanding operas. Tabuteau had to rise to meet the challenges of a taxing schedule, difficult repertoire, and very high artistic standards. These challenges undoubtedly improved his sight reading and technical abilities, refined his reed-making skills, and strengthened his physical endurance. Still a young professional, experience with outstanding artists ripened his musical maturity.

In 1915, Tabuteau became the principal oboist of the Philadelphia Orchestra, and held the position until his retirement in 1954. Leopold Stokowski conducted the orchestra for most of Tabuteau's long and successful tenure. Tabuteau was in the orchestra during numerous important American premieres, such as Mahler's Symphony No. 8 and Stravinsky's Rite of Spring. In addition, the orchestra under Stokowski produced many notable recordings and made several tours throughout the country, which helped it gain national recognition. The Philadelphia Orchestra under Stokowski set the standards for future American orchestras. Following

\footnotetext{
${ }^{30}$ Storch, Marcel Tabuteau, 48.
} 
Stokowski's retirement, Tabuteau played under Eugene Ormandy who maintained the orchestra's reputation. $^{31}$

Stokowski was a great visionary who constantly searched for new possibilities of tone color and nuance of phrasing. When Tabuteau joined the orchestra, Stokowski had been looking for an oboist who could satisfy his tonal vision. This situation with the Philadelphia Orchestra was ideal for Tabuteau. He responded to Stokowski's demands by refining his tone. In turn Stokowski encouraged individual expression, so Tabuteau was able to shine with his own musical voice alongside many prominent principal players.

\section{DEVELOPMENT OF THE AMERICAN SOUND}

Due to the musical demands of the conductor and the physical demands of the orchestra, Tabuteau developed a tone that was fuller, darker, and more flexible than the French ideal. Although he still retained the fundamental concepts that he learned from Gillet at the Paris Conservatory, several specific factors led to his modification of the characteristic French tone. Because of the significant alterations that Tabuteau made to the traditional French oboe tone and the proliferation of that tone through his influence as a teacher, Tabuteau is regarded as the "father" of the American school of oboe playing.

While the three orchestras for which Tabuteau played all influenced his tonal concept, it was the Philadelphia Orchestra under Leopold Stokowski that had the most dramatic impact. Stokowski demanded a rich, varied color palette from each player but he also wanted the winds to blend as a section. Musicians in the orchestra observed his interest in color, noting that he would often ask them to play tones of specific colors, such as a red tone or a blue tone. ${ }^{32}$

\footnotetext{
${ }^{31}$ Storch, liner notes.

${ }^{32}$ Neal, "The American Oboe School," 53.
} 
Tabuteau responded by developing a flexible embouchure. To play with a darker tone, he would position his embouchure closer to the tip of the reed. To produce a brighter sound, he would play closer to the binding. ${ }^{33}$ In addition, Stokowski set the pitch standard of the orchestra to A=440, lower than the pitch center of European orchestras. ${ }^{34}$ This flattening of pitch produces a darker oboe tone, and caused Tabuteau to make both embouchure and reed adjustments.

Tabuteau devoted a lot of time to experimenting with and refining his reeds. He needed reeds flexible enough to allow for the extreme ranges of dynamics and tone color that Stokowski insisted upon. He lengthened the traditional French scrape, which added lower partials to the tone. This lengthening of the scrape is now referred to as the "American" scrape. In addition, Tabuteau constantly experimented with changes in the gouge of the oboe cane. The gouge of the cane has a distinct effect on the overall pitch and tone quality of the finished reed; the changes Tabuteau made to the gouge further stressed the lower partials of the tone. ${ }^{35}$

Tabuteau's preference for Lorée oboes also contributed to the establishment of his school of playing. The tradition of using Lorée oboes was carried over from his studies with Gillet, for Gillet had close ties to the Lorée family and even helped them improve the instruments. Gillet insisted that his students use Lorée oboes, a practice that continued with Tabuteau and his students. ${ }^{36}$ While Lorée oboes already had a noticeably warmer and more resonant tone than other oboes, Tabuteau specified refinements to the bore of the instruments to further aid in achieving the tonal characteristics he sought. ${ }^{37}$

\footnotetext{
${ }^{33}$ Daniel Stolper, “A Conversation with Joseph Robinson,” The Double Reed 4, no. 1 (1981): 21.

${ }^{34}$ Storch, liner notes.

${ }^{35}$ Peter Hedrick, "Some Reflections on American Oboe Playing," Woodwind World 11, no. 5 (1972):10.

${ }^{36}$ Storch, liner notes.

${ }^{37}$ Hedrick, 10. "Some Reflections of Amercian Oboe Playing," 10. Specifically, modifications were made to the bore of the top joint and the bell of the oboe. Currently, manufacturers such as Lorée and Yamaha produce oboes with different bores for American and European style players.
} 
The size of the American concert halls was an additional influence on his playing. The French halls he played in before arriving to America were smaller than those he encountered in his new environment. Therefore, he had to develop a fuller, more resonant sound that would better project in larger halls. ${ }^{38}$ Acoustically, the addition of the lower partials creates a fuller sound in all dynamic ranges.

The international composition of the early American orchestras is another factor that influenced Tabuteau's tonal concept. For the most part, flute, oboe, and clarinet players were imported from France, but the bassoon, horn, and brass players were brought over from Germany. Because of the diverse national styles in the wind section, Tabuteau was forced to change his tone to blend in an unfamiliar timbral environment. ${ }^{39}$

\section{THE CURTIS INSTITUTE OF MUSIC}

When the Curtis Institute of Music opened in 1924, Stokowski asked Marcel Tabuteau, along with the other principal wind players of the Philadelphia Orchestra, to develop specialized training for American instrumentalists. The Curtis Institute was founded to train orchestral musicians to hold positions in American symphony orchestras because, by the 1920's, the union prevented orchestras from importing European players. The result was a lack of skilled wind players available to fill the positions of the major symphony orchestras. Ironically the Curtis Institute was created to train American instrumentalists, but it was the mostly European faculty of the Institute that was responsible for the formulation of an American style of playing.

Tabuteau taught at the Curtis Institute from 1925 until his retirement in 1954. For thirty years, Tabuteau taught private lessons and coached the woodwind ensemble. This ensemble

\footnotetext{
${ }^{38}$ Storch, liner notes.

39 Ibid.
} 
would perform an annual recital that was as celebrated for its high quality as it was infamous for the fear it instilled in the players. Tabuteau was an extremely demanding teacher. He wanted to prepare the students for the stressful life of an orchestral wind player. It was also his integrity and commitment to the music which caused him to be such an unrelenting teacher. He commanded discipline and insisted upon the perfection of notes, rhythms, intonation, dynamics, and articulation. He also required that each student perform with a clear understanding of the musical line.

A testament to his influence is the fact that a large majority of his students became the next generation of prominent oboists. Moreover, their students continued to develop distinguished careers. Currently, almost every professional oboist in America can trace their roots back to Tabuteau. ${ }^{40}$

\section{THE “TABUTEAU SYSTEM"}

Tabuteau's legacy can be attributed to the significant impact that his ideas concerning musical performance and interpretation had on the American style of oboe playing. Firmly rooted in music theory as well as the laws of nature and logic, Tabuteau spent his career refining his concepts and passing them along to future generations. His methods have come to be known as the "Tabuteau System," a term that he used himself. The "Tabuteau System" is a way to analyze and explain the art of phrasing by "breaking music down to its smallest and most vital components and relating it to life itself., ${ }^{42}$ Fundamental to his concept is the idea that music is a

\footnotetext{
${ }^{40}$ See Appendix A.

${ }^{41}$ This summary of the "Tabuteau System" was compiled using the following sources: David McGill, Sound in Motion, Neal, "The American Oboe School," Marc Mostovoy, "Marcel Tabuteau's Ideas on Music, Music Performance and Interpretation," and Tabuteau, Marcel Tabuteau Lessons.

42 Mostovoy, "The Tabuteau System," 541.
} 
living art and, just as a living being must breathe, so must music. Music is in constant motion. Tabuteau's system is a logical way to create forward motion, thus defining the musical phrase.

Tabuteau did not believe that music making is simply an emotional act of feeling. He understood that making music is a combination of feeling and thinking: "intelligent feeling." Only through proper analysis of the music's structure-phrase by phrase-can the player successfully deliver a meaningful performance. The written music only provides a blueprint, simple instructions for the performer to follow. The musician must analyze the music to form a plan for one's phrasing by revealing the music's "grammatical structure." Analyzing the surface elements of the music, such as dynamics and ornamentation, and relating them to the underlying elements, such as meter and harmony, accomplish this. In order to determine the "grammatical structure," the performer must be able to identify the function of each note. Once the function is identified, the skeletal structure of the phrase is likewise revealed. According to Tabuteau, only by identifying the "grammatical structure" of the music can the performer accurately communicate the music's true meaning.

The "Tabuteau System" is rooted in two main concepts that he used to teach phrasing, style, and musical expression to his students. The first concept was represented by a number system. Tabuteau used numbers that ranged from zero to ten to demonstrate the level of intensity each note within a line should receive. Intensity involves various components such as dynamics, timbre, and vibrato. ${ }^{43}$ Although the numbers were artificial, they served as a unit of measure by which Tabuteau could accurately reveal the shape of a line. Higher numbers represented more intensity, lower numbers represented less intensity.

\footnotetext{
${ }^{43}$ Terry Ewell, "A Bassoonist's Expansions upon Marcel Tabuteau 'Drive'," Journal of the International Double Reed Society 20 (July 1992): 27-30.
} 
Note grouping is fundamental to the "Tabuteau System," and he used the numbers to illustrate his ideas. Understanding how individual notes are grouped together enables the performer to play the music with forward motion. Note groupings are analogous to individual letters forming words in written language. Words then combine to form meaningful sentences, as do note groupings. Notes are grouped according to logical patterns based upon the rhythmic, melodic, and harmonic context of the phrase. Often more than one interpretation is possible. Also, the patterns may change more than once in a given passage.

In Lesson 8 of the Marcel Tabuteau Lessons, he played a short passage from Puccini's Madame Butterfly to illustrate the concept of note grouping and how he used numbers to "scale his expression":

Figure 2. Note Grouping illustrated in "Sakura" from Madame Butterfly ${ }^{44}$

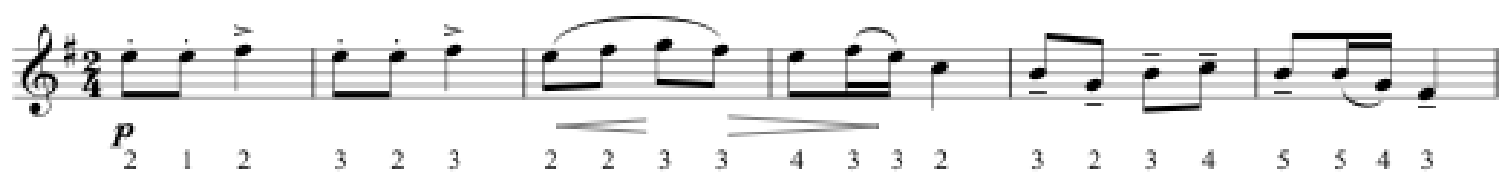

Each note of the melody received a number used to indicate the relative intensity each note should be given. Tabuteau only used consecutive numbers because his intention was to create a sense of line. Numbers are repeated as a means of creating proportion. For example, in the last measure of this excerpt, five is repeated on the first sixteenth note so that the descent to the Fsharp sounds even, and the second $\mathrm{B}$ on the sixteenth note does not get swallowed by the surrounding pitches.

The second concept of the "Tabuteau System" is what he calls "distribution." Distribution is the idea that each note has either an up or a down inflection. Tabuteau compared the "up/down" inflections in music to breathing, for each breath involves an inhalation and an

\footnotetext{
${ }^{44}$ Tabuteau, Marcel Tabuteau Lessons.
} 
exhalation. He often stated that "like us, music must inhale and exhale to be alive." ${ }^{45}$ Following the harmonic progression, an "up" inflection creates tension, whereas a "down" inflection results in a feeling of repose. Again, distribution is exemplified in the Madame Butterfly passage (down bow represents a down inflection, up bow an upward inflection):

\section{Figure 3. Distribution illustrated in "Sakura" from Madame Butterfly ${ }^{46}$}

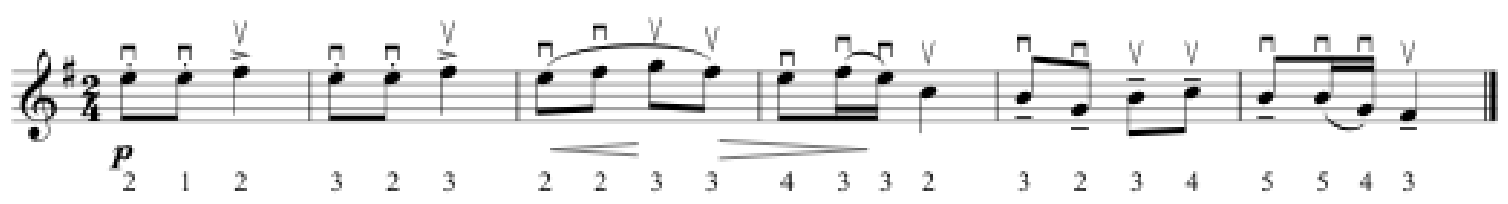

In Lesson 3, Tabuteau cautions the performer to "remember the progression of numbers is not exactly a crescendo or a diminuendo. It is rather a scaling of color." ${ }^{47} \mathrm{He}$ equates this notion with the bowing distribution on the violin. ${ }^{48}$ The tone color over the fingerboard is mellower, but as the bow approaches the bridge, it becomes brighter. To achieve a similar result on the oboe, variety of color is achieved by the position of the reed on the lips. The same note produced on the tip of the reed changes gradually as one moves toward the binding. This technique requires a flexible embouchure.

The primary method of producing a louder dynamic on the violin is to increase bow pressure on the strings. More bow speed will also increase the volume; however, it is possible for the violinist to play softly with fast bow speed. This technique produces a different timbre (referred to as flautando). Because bow pressure and bow speed are separate methods of tone production, the violinist is able to play pianissimo with a lot of tonal intensity.

\footnotetext{
${ }^{45}$ Tabuteau, Marcel Tabuteau Lessons.

46 Ibid.

${ }^{47}$ Ibid.

48 John de Lancie claimed that Tabuteau's ideas about bow distribution were influenced by a book called Die Hohere Bogentechnik (The Superior Bow Technique) by Lucien Capet (1927). Capet divided the bow into sections. To create different colors, the player needs to master control of each section. By controlling each section, the violinist is able to achieve the variety of tone color necessary for musical expression. This concept parallels Tabuteau's idea of controlling the wind. See Melissa Steven's article, "Follow-up to the Interview with John de Lancie" The Double Reed, vol. 25, no. 4 (2002) for a thorough summary.
} 
Just as violinists place notes "on the bow," oboists place notes "on the wind." To play softer, the oboist has two possible techniques that result in different tone colors. One possibility is to decrease the air support, which creates a soft and weak sound. A more intense pianissimo is produced by maintaining strong air support and increasing the lip pressure around the reed.

When playing the oboe, the wind support should be intense and constant, for dynamics and color changes are only possible with the proper wind support. Therefore, wind is extremely important in creating the musical line. The oboist changes color by altering the speed of air, changing the position of the reed, or changing the amount of pressure exerted on the reed with the lips. Dynamic shifts result from the amount of air allowed to pass through the reed, either by lip pressure, speed of wind, or both. Thus, like string players, oboists can achieve various color changes in all dynamic levels. Moreover, the more proficient the player, the more coloring changes are possible.

The "Tabuteau System" has been preserved mainly through oral tradition; however, some of his students have made more permanent records of his teaching. One notable source is a series of recordings made by Wayne Rapier entitled Marcel Tabuteau Lessons. This recording is a compilation of twelve lessons in which Tabuteau outlines his fundamental concepts. Earlier attempts to record his ideas were made when his friend Waldemar Wolsing visited him in Nice in 1964 and recorded Tabuteau as he narrated some of his ideas. Although these recordings are not as systematic as Marcel Tabuteau Lessons, some of his fundamental concepts of oboe playing are documented, and Laila Storch includes them in her biography of Tabuteau. ${ }^{49}$

What is most significant about the "Tabuteau System" is that it is a universal method that can be used by any performer, regardless of instrument. As David McGill indicates in Sound in Motion,

${ }^{49}$ Storch, Marcel Tabuteau, 523-544. 
American woodwind instrumentalists today are aware of the existence of an American style of woodwind playing, but most are, understandably, blithely unaware of its origin. The roots of a rationalized system of musical phrasing, which led to the creation of this distinctly American woodwind style, can be traced back to one legendary performer and teacher who began to open the eyes of his students in Philadelphia beginning in the 1920s. This well-documented stylistic phenomenon-born less than a century ago and preserved on disk - was largely brought about through the efforts of Marcel Tabuteau. He happened to be an oboist, but his message was universal. ${ }^{50}$

Tabuteau was such an influential teacher in terms of his ideas and methods for conveying the meaning of a phrase that in his last ten years at the Curtis Institute, he coached string ensemble classes in addition to the woodwind ensemble. Prominent wind and string players alike have credited Tabuteau as a main influence upon their performance skills.

\section{$\underline{\text { PEDAGOGY }}$}

Tabuteau emphasized that beautiful tone production is essential in fundamental training, for it is with this tone that one can achieve the highest level of artistry and expression. ${ }^{51} \mathrm{He}$ believed that the oboe was the closest of all instruments to the human voice in terms of expressive capacity. Perhaps the years that he played with the Metropolitan Opera Orchestra along with the color demands of Stokowski led Tabuteau to this conclusion. He believed that "a fine oboist can produce as many as fifty different tones on one note, just as a singer can vary the colorings of the voice in an infinite number of ways. Therefore the oboist must think vocally." ${ }^{52}$

In order to achieve this absolute control, the oboist must learn that the quality and intensity of tone is determined by the pressure and speed of the wind along with the position of the lips on the reed. Vibrato is also a product of wind and embouchure, for a true oboe vibrato is

\footnotetext{
${ }^{50}$ McGill, Sound in Motion, 2.

${ }^{51}$ Marcel Tabuteau, "Marcel Tabuteau of Philadelphia Orchestra Summarizes Training," trans. Robert Sabin. The Double Reed 22, no. 1 (1999), 107.

52 Tabuteau, "Marcel Tabuteau of Philadelphia Orchestra," 107.
} 
produced by the intensity of the player's wind. As the speed increases, the embouchure should be released, otherwise a tone that sounds thin and pinched will result.

Tabuteau's students all discuss how he would begin lessons with long tone exercises. He used numbers ranging from one to nine and had the students blow faster as the numbers increased while releasing lip pressure. Tabuteau taught that the pressure should be behind the note before playing, like turning on a "faucet of water." ${ }^{, 53} \mathrm{He}$ urged his students to hear the tone in their head before beginning. Variations of this long tone exercise included articulating on the single note, and playing long, sustained five note scale passages $1-5-1$, with the proper up/down inflections to emphasize an implicit underlying harmony. While playing slow scales, the students were reminded to "play between the notes," connecting the notes with the wind for a perfect legato the way a string player uses the bow. ${ }^{54}$ Hence, a fundamental aspect of his pedagogy was the use of long tones and slow scales in which the student learned all the tools of proper tone production and inflections necessary to play the line.

Tabuteau stressed the importance of musical intelligence. The student should have a solid foundation in solfège, piano, theory, and voice, and develop the art of phrasing from the beginning. He would tell his students that if they "think beautifully they will play beautifully." ${ }^{55}$ The honing of musical intelligence is the basis for his development of the "Tabuteau System." In addition to long tones and scales, Tabuteau focused on exercises from the Barret Oboe Method, and later Ferling, Brod, and Gillet etudes. ${ }^{56}$ Storch recalled that Tabuteau would always talk about the "line" of the music, as she performed these exercises. Also, one should not "practice a lesson, and then dismiss it from your mind, because you have to keep putting the same things

\footnotetext{
${ }^{53}$ Storch, Marcel Tabuteau, 225.

${ }^{54}$ Ibid.

${ }^{55}$ Tabuteau, "Marcel Tabuteau of Philadelphia Orchestra," 108.

${ }^{56}$ Stevens, "Marcel Tabuteau," 33.
} 
into practice." ${ }^{57}$ As if to emphasize this fact, Tabuteau made his students repeat the same exercises the following lesson in a different key. Thus, it is evident that Tabuteau believed in teaching tone production and phrasing through the use of long tones, scales, and etudes. Because he maintained that the job of a teacher is to develop the student's own ability to be his or her own teacher, one should apply the lessons taught through exercises and etudes to the actual repertoire.

In terms of the orchestral repertoire, Tabuteau asserted that a flawless performance is not easy to accomplish; rather, it is achieved through years of hard work, intense practice, and guided, intelligent decisions about the music. For example, any orchestral player must know the whole score and how his or her part fits. Only a player with these refined skills may respond to the conductor's wishes. ${ }^{58}$ His system of thinking with numbers and inflections assured that the musical line always had a solid foundation, rather than sounding aimless. Storch observed that Tabuteau could place every note "exactly at a certain spot as if on a micrometer."

In addition to his approach to the orchestral repertoire, Tabuteau also emphasized the value of studying the solo repertoire for the oboe from "Handel to Hindemith." ${ }^{60}$ This repertoire will guide the student to a sense of style and phrasing. He also believed that the students ought to make their own reeds and master the technique of English horn playing. The student should play in ensembles as soon as they are ready in order to develop a sense of security from the beginning. Finally, he observed that each student is an individual and should be treated as a particular problem to solve. Moreover, a good musician is always able to develop his or her own studies and improvements by individual observation and assessment. ${ }^{61}$

\footnotetext{
${ }^{57}$ Storch, Marcel Tabuteau, 240.

58 Tabuteau, "Marcel Tabuteau of Philadelphia Orchestra," 108.

${ }^{59}$ Storch, Marcel Tabuteau, 236.

60 Tabuteau, "Marcel Tabuteau of Philadelphia Orchestra," 108.

61 Ibid.
} 


\section{TEACHING STYLE}

Anyone who came under the tutelage of Tabuteau attested to his "strong personality" and "mercurial temperament." ${ }^{92}$ His students all spoke of how they were both shattered by his explosive criticisms and brought to roaring laughter by his colorful anecdotes and jokes. For example, "Your tone...your tone....it is like you are walking along a beach and you see a clam. It looks perfectly good-you open it up and it is just full of mud." Or, "Your playing is like saltwater taffy. You see all beautiful colors-red-yellow-blue-but they all taste the same." So, although it was not always easy for his students to keep their perspective, they were often amused. Above all, Tabuteau had a strong and lasting impact on their lives. In an interview, John Mack stated,

Tabuteau could make you very uncomfortable, and I think in a way he enjoyed doing that. He could really lean on you. I have been told by a friend of mine who has retired from his position that he would never be able to forgive Tabuteau for what he did to him at Curtis. He also said, 'I would not have accomplished what I had while I was in school had it not been for my over-riding fear of that man.' I think I'm quoting him verbatim. I thought, 'I have long ago forgiven him for any lumps I ever got, because I got so much from him.' He hardened you. ${ }^{63}$

This author experienced the influence of Tabuteau's personality and teaching style while attending the John Mack Oboe Camp. ${ }^{64}$ Days were spent in masterclasses that focused on the Barret etudes and orchestral excerpts. Mack would often quote Tabuteau when coaching the students. To further attest to the power that Tabuteau's dominating, enigmatic personality had upon his students, evenings of the camp were dedicated to Mack's retelling of Tabuteau anecdotes, often recounted in imitation of his thick French accent.

Above all, Tabuteau taught his students that they should learn from every experience in life. His own life was full of rich experiences and places. Storch noted him as saying, "You must

\footnotetext{
${ }^{62}$ Stevens, "Marcel Tabuteau," 45.

${ }^{63} \mathrm{Ibid}$.

${ }^{64}$ John Mack, John Mack Oboe Camp (masterclass, North Carolina, June, 2001).
} 
be open to everything-learn from everything. The more you take from the world, the more you can give to the world. Develop your personality and do more than shroom and scratch ten hours a day!",65

\section{CONCLUSION}

Tabuteau's influence upon American musical pedagogy cannot be overestimated. He was an extraordinary musician who developed a systematic and universal approach to phrasing that inspired wind players, string players, pianists, and conductors alike.

Prior to his long career as an oboist and pedagogue in America, the country did not have its own school of oboe playing. Tabuteau is credited as the "father" of the American school of playing due to the changes he made to the oboe tone and style of reed making. In fact, by the time he retired from the Curtis School and the Philadelphia Orchestra, most of the professional oboe players in America were "homegrown" students of Tabuteau.

Certainly any talented oboist in similar circumstances would have an impact, but Tabuteau stands apart from the other oboists who immigrated to America at the same time. He possessed a creative imagination, charismatic personality, and an ability to clearly articulate his ideas. These attributes are responsible for his remarkable place in history.

\footnotetext{
${ }^{65}$ Storch, "Marcel Tabuteau". To the World's Oboists 2, no. 1 (1974), http://idrs.colorado.edu/Publications/TWOOboist/TWO.V2.1/TWO.V2.1.Tabuteau.html (accessed November 13, 2009).
} 


\section{CHAPTER 3: ROBERT BLOOM}

Robert Bloom (1908-1994) has been hailed as the "Pavarotti of the Oboe." ${ }^{966} \mathrm{He}$ was one of Tabuteau's first students at the Curtis Institute and went on to have a long, successful career as an orchestral, solo, and chamber musician. Bloom was praised for his vocal tone and his "unique, fearless expressiveness ${ }^{967}$ as a performer. He was equally successful as a pedagogue and his students went on to hold top positions in American orchestras. Notable students of Bloom include Ray Still, Humbert Lucarelli, Richard Killmer, Robert Sprenkle, Alan Vogel, and David Weiss. ${ }^{68}$

Oboe scholars owe a debt of gratitude to Sara Bloom-Robert Bloom's wife and former student-for her tireless efforts to preserve his legacy. She has devoted a large portion of her professional life, much of this in collaboration with Robert, to publishing his work. In 1998, she released The Robert Bloom Collection: Solo and Chamber Music for Oboe. This multi-volume set includes eighteenth-century works edited by Robert Bloom, along with several original compositions. ${ }^{69}$ In 2009, Sara Bloom published Robert Bloom: The Story of a Working Musician..$^{70}$ This work, in which she acted as both editor and contributor, is notable because it contains a memoir of Bloom as well as his pedagogical treatise, The Oboe, A Musical Instrument, as dictated to Sara from 1975-76. Because of this book, thorough records of his instructional methods have been preserved.

66 Norman B. Schwartz, "The Pavarotti of the Oboe: Robert Bloom (1908-1994)," http://cranberryisles.com/photos/robert_bloom.html (accessed August, 2010).

${ }^{67}$ Ibid.

${ }^{68}$ Sara Lambert Bloom, Robert Bloom, 399-408. Sara Bloom offers a thorough list of students in this source, complete with places and years of study. See pages 399-408.

${ }_{69}$ Dan Stolper, "The Robert Bloom Collection: Solo and Chamber Music for Oboe (Review)," Notes 58, no. 1 (September, 2001): 186-191.

${ }^{70}$ Robert Bloom, "The Oboe, A Musical Instrument," in Robert Bloom: The Story of a Working Musician, ed. Sara Lambert Bloom (United States: Sara Lambert Bloom, 2009). 
Robert Bloom was raised in Pittsburgh, Pennsylvania. Born into a family of musicians in 1908, his father was a prominent cantor and his siblings were also musically gifted. While attending local public schools, Bloom sang in his father's choir and studied several instruments. In 1925, he began studies in cello and music education at Pittsburgh's Carnegie Institute of Technology (now Carnegie Mellon University). Bloom began playing the oboe after being persuaded by the conductor of Pittsburgh's All-City Youth Orchestra. Shortly thereafter, in 1927, he auditioned for Tabuteau and was accepted at the Curtis Institute. Curtis had opened only three years prior; consequently, Bloom was in the first generation of Tabuteau's oboe students. Tabuteau's relatively short tenure at this point is noteworthy because it is unlikely that a novice oboist would have been accepted to Tabuteau's studio or, indeed, to the Curtis Institute at any other point in history. Fortunately for Bloom, at the time of his acceptance, Tabuteau was drawn to a student's aptitude more than his experience.

Following just three years of study with Tabuteau at Curtis, in 1930 Bloom began his orchestral career as second oboist with the Philadelphia Orchestra. He was later moved to solo English horn, and remained in the orchestra in that position until 1936. Bloom then briefly played as principal oboist with the Rochester Philharmonic until 1938, when he was offered the principal position of the National Broadcasting Company (NBC) Symphony Orchestra, a group organized and conducted by the celebrated Arturo Toscanini.

For several years, Bloom and Toscanini worked closely together, forming a deep relationship of mutual respect. Toscanini had known Bloom since his years at Curtis, and had always admired his playing. The maestro often pleaded with the players of the orchestra to "PUT something! Do something bad, but do SOMEthing," ${ }^{\text {11 }}$ an expression that Bloom frequently repeated in lessons with his own students. For an expressive musician like Bloom, playing under

\footnotetext{
${ }^{71}$ Sara Lambert Bloom, "Sara Bloom on Robert Bloom- The Legacy," The Double Reed 22, no. 4 (1999): 47.
} 
such a conductor undoubtedly inspired him. Bloom respected that Toscanini, often called a "literalist," was able to remain devoted to the score while simultaneously making sound, artistic decisions that allowed for the most musical expression. ${ }^{72}$

Unlike many of his contemporaries and the Tabuteau students who graduated after him, Bloom left his full time orchestra position and struck out on his own in New York City. ${ }^{73}$ His self-assuredness and confidence in sight-reading resulted in a lucrative career, for he became one of the highest paid free-lance wind players in the city. He was among a select group of session musicians who frequently recorded with orchestras for such labels as RCA Victor and Columbia. $^{74}$

Bloom distinguished himself as a soloist. Note this letter from Stokowski, whom Bloom often played under in the recording ensemble known as Stokowski and the Orchestra, "Dear Mr. Bloom, You played so wonderfully in the Bach, I feel I must write to tell you what deep musical satisfaction I had from listening to your solos, and to [sic] making music with you." 75 It is remarkable that Bloom never seemed daunted by a conductor or performance situation. This bold attitude certainly set him apart from others, yet Sara Bloom points out that people remember his "sunny disposition and his admonition to take our work very seriously but not ourselves." 76

In 1946, William Scheide founded the Bach Aria Group in New York City. In post-war America, a Baroque revival was in vogue. The purpose of the group was to perform the cantatas of J.S. Bach, music that was challenging and obscure at the time. Rather than selecting Baroque specialists, Scheide sought out the best free-lance players in the city. The result was a

\footnotetext{
72 S. Bloom, "Sara Bloom on Robert Bloom," 47.

${ }^{73}$ Schwartz, "Pavarotti of the Oboe," Supposedly, Bloom left the NBC Symphony after management refused to grant him a raise. One can assume that he was hurt, given the close relationship he had with Toscanini.

${ }^{74}$ Ibid.

75 Ibid.

${ }^{76}$ S. Bloom, "Sara Bloom on Robert Bloom," 51.
} 
performance group of highly skilled, artistic musicians who collaborated to create the standard for Baroque performance practice. With the Bach Aria Group, Bloom worked closely with such musicians as Julius Baker, flute, Bernard Greenhouse, cello, and Jan Peerce, tenor, Caruso's successor in the Metropolitan Opera. Bloom was a key member of the group from 1946 until his retirement in 1980. His work with the Bach Aria Group further distinguished him as a solo and chamber musician through various recordings and performances throughout the country. It also raised his artistic and scholarly standards, which resulted in the subsequent publication of The Robert Bloom Collection.

Bloom was passionate about passing his knowledge on to future generations of oboists. His teaching spanned six decades. Throughout his career, he taught at several prestigious institutions, including Eastman School of Music (1936-37), Yale School of Music (1957-76), Hartt School of Music (1967-75), Manhattan School of Music (1967-72), The Juilliard School (1973-81), and Philadelphia College of the Performing Arts (1978-85). ${ }^{77}$ Bloom also taught oboe at several summer festivals, including the Sarasota Music Festival where he coached for 23 years.

The most significant aspect of his teaching philosophy is that the student learns to become his or her own musician, capable of forming ideas autonomously. As Sara states, "He took great pride in having his pupils sound like individuals." ${ }^{" 78}$ This goal was attained through his emphasis on the creation of proper performance editions, a principle that he taught through example. Bloom was well-known for his skill at composing ornamentations and performance

\footnotetext{
${ }^{77}$ S. Bloom, Robert Bloom, 399-408. In this noteworthy list, Sara chronicles each student, along with the degree received with Bloom and their current credentials. She then lists students that studied with him privately throughout his life. It is an extraordinary catalog of distinguished oboists over the past several decades, and reveals his powerful influence on the American school.

${ }^{78}$ S. Bloom, "Sara Bloom on Robert Bloom," 49.
} 
editions, as evidenced by The Robert Bloom Collection. ${ }^{79}$ He focused on music of the Baroque period, specifically J.S. Bach, because Bach wrote his ornaments and elaborations completely, whereas other composers from the same period composed only sketches (as was the stylistic practice). Once the students were able to make choices after "mastering principles of style and harmony as well as general aesthetic choices idiomatic to the oboe," they could compose their own elaborations. ${ }^{80}$ In acquiring the knowledge to elaborate upon the score, he advocated reading eighteenth-century authorities, such as The Interpretation of Early Music by Robert Donnington. He regarded reading as necessary because even the experts, for example C.P.E. Bach and Quantz, had different opinions regarding performance practice. For this reason, it is up to the modern performer to make independent, yet educated decisions. Alejandra Garcia Trabucco, a Fulbright scholar who studied with Sara at the Cincinnati College-Conservatory, summarized his philosophy of musicianship as follows:

In the prefaces [of The Robert Bloom Collection], you can tell different layers intertwined: the musical analysis, the historical information always in context of a personal interpretation, and the human stories connected with the piece, which most times involve world renowned musicians (from Toscanini to Perlman), are presented to the reader as an indivisible whole, rich and coherent. There is a strong message to both the student and the professional oboist, through the life and work of Mr. Bloom: find out about the historical context of each piece, make up your mind, choose, try, think, trust your musical instinct, hear your colleagues, admire and learn from those who are great, extend your sources. It is hard to find nowadays such an exemplary life. ${ }^{81}$

Although Bloom was adamant that the student becomes an individual interpretive artist, he was strict about the fundamental aspects of tone production. He was motivated by the fact that without mastering the proper techniques necessary to play the oboe, it is impossible to

\footnotetext{
${ }^{79}$ One striking example is his ornamentation of the second movement of the Marcello Concerto for oboe. Most oboists perform the same elaborations that J.S. Bach composed when he transcribed it for keyboard. Bloom, however, composed his own for this movement so that the ornamentation is more idiomatic for the oboe. Bloom's elaboration is included in the Robert Bloom Collection.

${ }^{80}$ S. Bloom, "Sara Bloom on Robert Bloom," 49.

${ }^{81}$ Ibid., 51.
} 
adequately express the music. While Bloom was dogmatic about his approach to tone production, he was sincere in his preface to The Oboe, a Musical Instrument about "not advocating a universal school of oboe playing." ${ }^{82}$ In fact, he stated that he did not "find fault with other schools." ${ }^{, 83}$ Bloom was merely concerned with analyzing his approach so that he was able to teach others. However, if a student liked a different school, then according to Bloom, "that is his prerogative and I think he should stick to it." ${ }^{84}$ This attitude is aligned with his emphasis on individuality and contrasts with that of his contemporaries, for his career spanned the period when the "American school" was codified.

The foundation of Bloom's approach to oboe performance was related to the physical act of playing the instrument. He compared this to the way singers think about their "instrument." In fact, Bloom regarded the human voice as "the highest form of expression" 85 and strove to make his playing seem as natural as singing, despite the fact that the oboe is a resistant instrument, quite different from the human voice. In vocal training, the singer is concerned with resonance, how they project to an audience, as opposed to how they hear themselves. Vocal technique focuses on capturing a physical sensation in the body, locating the source of strong resonance, and learning to project from this internal fount. Bloom called this idea the "physical and sensual sensation" and claimed that it is the "secret of playing." 86 The physical sensation he referred to entails the actual athleticism necessary to play the oboe: strength, coordination, balance, and flexibility. The sensual sensation is comprised of using controlled physicality to express the music. $^{87}$

\footnotetext{
${ }^{82}$ R. Bloom, "The Oboe, A Musical Instrument," 299.

${ }^{83}$ Ibid.

${ }^{84}$ Ibid.

${ }^{85}$ Ibid., 300.

${ }^{86}$ Ibid.

${ }^{87}$ Ibid.
} 
For Bloom, posture was a key element in tone production and natural oboe playing. Moreover, he wanted people to enjoy the music he was making. So often, the audience is amazed at the apparent physical strain of oboe performance, but Bloom saw this as a distraction. Therefore, he practiced in front of a mirror, and strove to make his playing seem comfortable and natural. He felt that one should appear as relaxed as if talking. He taught his students to look in the mirror and bring the oboe up to the face, as opposed to keeping the head down. ${ }^{88}$ This technique seems self-evident but a large proportion of students tend to lower their heads to the instrument, resulting in poor posture. Since everyone has a different body, the stance can vary slightly for each person when practicing with a mirror. Because of this, Bloom would help find the most natural playing position for each individual. A natural stance is quite different from that created by standing with one's back against the wall, a technique employed by de Lancie when teaching posture. While this method does train the student to stand straight, it is unnaturally rigid.

Bloom formed his embouchure by bringing the oboe up to his head, placing the reed on the red part of his bottom lip, and bringing the reed into the mouth. The upper lip was then brought over the top teeth. While some oboists maintain that no teeth should be involved with embouchure formation, Bloom observed that for him, the bottom teeth act as a "backstop" for his lower lip. ${ }^{89}$ Because the oboe is a double reed instrument and therefore must be played on both the upper and lower blades of the reed ${ }^{90}$ the upper lip acts as a stabilizer. The amount of lip and teeth used is dependent upon the individual because the fullness of lips varies. However, he

\footnotetext{
${ }^{88}$ R. Bloom, "The Oboe, A Musical Instrument," 300.

${ }^{89}$ Ibid., 301.

${ }^{90}$ It can be noted that most oboists in the American school observe this fact as well as the notion that the lips are used unequally, and that usually the bottom lip is favored.
} 
cautioned that the oboist should never stretch the lips over the teeth, for there should always be an inside pucker of the lips. ${ }^{91}$

Bloom recognized two sets of muscles that contribute to the embouchure. The first set is the powerful jaw muscles that create the up and down motion of the lower jaw. To compensate for the biting motion caused by these muscles, the oboist must also utilize the muscles that stretch over the cheek to create sideways pressure on the reed. By engaging these muscles, the lips are automatically pushed forward into a pucker. The oboist must then keep the lips turned inward where they are compressed with the bite, using the jaw muscles. For Bloom, it was necessary to use the cheek muscles to create pressure on the sides of the reed, because this allows the lips to remain soft. Keeping the lips soft provides more potential for controlling color and dynamics changes. ${ }^{92}$

The amount of reed taken into (or, more accurately, not taken into) the mouth was of the utmost importance to Bloom. He was preferred as little reed as possible. One should play on the tip of the reed because the tip is the thinnest part, thus, the easiest to control. The player can think of bringing the reed in only as far as the tip of the tongue is allowed to touch the tip of the reed. Bloom created an exercise that demonstrated the proper amount of reed allowed to enter the mouth. He suggested playing a few comfortable notes and then opening the mouth (keeping the reed placed against the bottom lip) and checking in the mirror how much reed is extended over the bottom lip. For Bloom, no amount of extension was acceptable. ${ }^{93}$ Finally, similar to other oboists in the American school, he used different amounts of reed in his mouth depending on

\footnotetext{
${ }^{91}$ R. Bloom, "The Oboe, A Musical Instrument," 301.

92 Ibid.

${ }^{93}$ Ibid., 302.
} 
register. He maintained that the lips must "travel with the reed over the teeth." ${ }^{94}$ In this way, the oboist is still playing on the tip of the reed at all times.

Like Tabuteau, Bloom drew a comparison between the oboist's use of air with the string player's use of the bow to produce sound. He believed that the air should flow freely, only controlled by the embouchure. This is an important concept because it is at this point that many oboists lose their natural approach, hence playing the instrument becomes physically demanding. Any amount of tension is "false work." Bloom understood that "as one plays, one liberates the tone, letting it come out instead of restricting it." 95 The freedom from tension was one of the first issues that Bloom would address in lessons with new students, often encouraging the oboist to "loosen up and get some air into the instrument." ${ }^{96}$ Bloom believed that the oboist must not trap air in the throat. The throat should therefore remain open and not be used to control dynamics or the stability of the high notes. ${ }^{97}$

The proper use of air plays a key role in the production of vibrato. Bloom preferred to teach vibrato indirectly. Again, drawing a comparison with vocal technique, he believed it should be produced naturally, as a product of efficient air support. He claimed that: "No singing teacher in his right mind would ever spend time teaching a singer to make a vibrato. There is absolutely no reason why the same should not be self-evident on any wind instrument." 98 Consequently for Bloom, vibrato was produced neither by the throat, nor the stomach. For him, that ongoing debate among wind players is inconsequential.

\footnotetext{
${ }^{94}$ R. Bloom, "The Oboe, A Musical Instrument," 302. This notion of a flexible embouchure is an important characteristic of the American school because other European styles are immobile and rely on the bite and/or throat tension to stabilize the upper register.

${ }_{95}$ Ibid., 304.

${ }^{96}$ Ibid., 305-306.

${ }^{97}$ Ibid., 308.

${ }^{98}$ Ibid., 309.
} 
Bloom noted the American school's obsession with the production of a "dark tone" and pointed out that this preoccupation is reactionary. ${ }^{99}$ American players were searching for a timbre that contrasted that of the European, which seemed to emphasize only the upper partials of the sound. However, for Bloom the most expressive oboe sound projects all frequencies, both upper and lower. He recognized that a tone that is too dark, thus dampened and woody, is just as uninteresting as a tone that is too bright and nasal. ${ }^{100}$ Again, he drew a comparison with singers. Singers that only use their chest voice are equally as unimpressive as those who only use a head voice. The best means for expression is attained through a combination of all frequencies in the sound. ${ }^{101}$ In addition, Bloom observed how the tone quality relates to resonance. A tone that is too dark will not resonate as well as one that is balanced. ${ }^{102}$

Bloom employed embouchure changes to control both dynamics and color. Rapid air speed was a constant in tone production for him, so he always drew upon his embouchure to manage the reed. Even when playing as loud as possible in an orchestral tutti, he commanded the tone with the embouchure so that a diffuse sound would not result. Like Tabuteau and his disciples, Bloom exerted a great amount of air speed when playing softly, dampening the sound with the embouchure. Controlling the tone with the embouchure becomes more effortless as the muscles strengthen. Bloom recommended détaché articulation exercises to strengthen the embouchure, wherein the oboist used the embouchure to stop the sound between repetitions as opposed to the tongue. ${ }^{103}$

\footnotetext{
${ }^{99}$ R. Bloom, "The Oboe, A Musical Instrument," 311.

${ }^{100}$ When Tabuteau originally evolved the French tone, he was seeking a wider tonal spectrum-not necessarily an opposing timbre. While he did add lower partials to the sound, he was in favor of a variety of color for the maximum amount of expression.

${ }^{101}$ R. Bloom, "The Oboe, A Musical Instrument," 312.

${ }^{102}$ Ibid.

${ }^{103}$ Ibid., 313.
} 
Another topic pertaining to embouchure formation and tone production was Bloom's idea of "homogenizing the sound." $104 \mathrm{He}$ recognized that certain notes on the oboe are not as focused as others. The player must learn to make all notes in a scale sound equal. He recognized that this can be accomplished by adjusting the embouchure and air speed for certain pitches, such as $\mathrm{C}^{5}$. Rather than shying away from the note, like most oboists tend to do, he recommended speeding the air and dampening the sound with the embouchure. ${ }^{105}$ Bloom asserted, "One must feel the sound; one must feel the texture. It is up to the player to work on the bad notes on the instrument to make them match the good notes."106

Bloom understood that oboists often have to play on reeds that are less than ideal and, within reason, must develop the ability to change the sound of the reed with the embouchure. Refining a reed necessitates a delicate balance because "the embouchure, not the reed, plays the oboe." ${ }^{107}$ If the reed is too weak, usually with a small opening and limited vibration, the student may play with an open embouchure but tighten the throat and chest. If the reed is too stiff, it is difficult to control the embouchure, which makes color and dynamic changes difficult. Too much or too little resistance and flexibility in a reed result in an inability to sing through the reedBloom's ultimate goal. For these reasons, the player needs to learn the parameters of what is considered a "workable" reed. These parameters vary between players, given the relative strength of the embouchure. ${ }^{108}$

Bloom was among the first generation of American born and trained musicians who played a prominent role in the country's orchestras and conservatories. Moreover, he was one of

\footnotetext{
${ }^{104}$ R. Bloom, "The Oboe, A Musical Instrument," 314.

105 Ibid.

106 Ibid.

${ }^{107}$ Ibid., 313.

${ }^{108}$ Ibid. These observations are actually articulated by Sara, who assisted Robert in adjusting students' reeds. I have noticed the same results in my own studio, especially when I first encountered the use of European style reeds at Mahidol University in Bangkok, Thailand. The relationship between the reed and embouchure, air support, and throat/chest tension is a precarious balancing act!
} 
Tabuteau's first students at the Curtis Institute. This fact is notable because Tabuteau codified his performance practice and pedagogy throughout his career, so Bloom's instruction was rather different from that of later students, such as Mack. Bloom also possessed an independent spirit that pervaded his career path and approach to playing the oboe, and ultimately led to his long tenure with the Bach Aria Group, a performance atmosphere that greatly refined his philosophies on tone production and musicianship. Moreover, it offered a setting that allowed him to stand out as a soloist and chamber musician, more so than his contemporaries who were mainly orchestral players. Hence, Bloom had a unique perspective and approach to playing the oboe, as compared to other oboists from the American school.

Bloom upheld the importance of being a complete musician. He drew inspiration from many types of performing musicians, such as conductors and string players. But, more than anything else Bloom sought to emulate the human voice with his playing. He accomplished this ideal; Bloom's tone is remembered for its vocal quality. In fact, Ray Still (b. 1920), the most prominent American oboist of his generation who did not study with Tabuteau, was drawn to Bloom because of his singing, vibrant sound. Wayne Rapier summarized it best when he stated that Robert Bloom was "one of the greatest singers...who happened to play the oboe." 109

\footnotetext{
${ }^{109}$ Schwartz, "The Pavarotti of the Oboe."
} 


\section{CHAPTER 4: JOHN DE LANCIE}

In 1954, John de Lancie replaced Tabuteau at the Curtis Institute and became principal oboist of the Philadelphia Orchestra upon the latter's retirement. De Lancie's long, distinguished career earned him a legendary reputation as both a performer and a pedagogue. By continuing the principles of tone production and musical phrasing that he learned through Tabuteau, de Lancie and his students established a style of playing that has come to be known as the "Philadelphia style."

Many of de Lancie's students have earned top positions throughout the United States. In addition to their achievements in the performance arena, his students are also accomplished in the academic realm. Although de Lancie did not record his pedagogical ideas, his students are largely responsible for much of the scholarly literature about American oboe pedagogy. Jay Light, Marylin Zupnick, David Weber, Martin Schuring, and David McGill ${ }^{110}$ have all made scholarly contributions. As a result, many of de Lancie's ideas concerning musical expression and tone production can be extracted from these secondary sources.

De Lancie was born in Berkeley, California in 1921. At age fifteen, he moved to Philadelphia, where he studied with Marcel Tabuteau at the Curtis Institute from 1936-1940. Upon his graduation at age nineteen, he joined the Pittsburgh Symphony as principal oboe under Fritz Reiner. In 1942, de Lancie's orchestral career was interrupted when he served in the U.S. military and played in the Army Band. He returned to Philadelphia in 1946 where he joined the Philadelphia Orchestra as assistant principal oboist, alongside his mentor Tabuteau. De Lancie became the associate principal in 1948, and replaced Tabuteau as principal when he retired in 1954. At the same time, de Lancie succeeded Tabuteau at the Curtis Institute of Music, where he

\footnotetext{
${ }^{110}$ Although McGill is a bassoonist, he worked closely with de Lancie at the Curtis Institute as a student in his woodwind classes. He credits de Lancie with much of what he learned regarding musical ideas.
} 
taught oboe and wind classes until 1985. In 1977, de Lancie retired from the orchestra upon his appointment as director of the Curtis Institute of Music. ${ }^{111}$ He kept the position for eight years until "his insistence on high standards and his inability to compromise" 112 created discord between de Lancie and the administration. He formally resigned in 1985. He faced similar conflicts in his next position (1987-1992) as the founding music dean at the New World School of the Arts. Eventually, he moved back to California and joined the faculty of the San Francisco Conservatory of Music. He remained in California until he passed away on May 17, 2002 from leukemia. $^{113}$

De Lancie expanded the oboe repertoire, reclaiming its status as a solo instrument by commissioning new concertos and performing rarely-heard works. His advocacy for enlarging the repertoire began at the end of World War II, when he was just twenty-four and was fortunate enough to meet Richard Strauss. It was during this meeting that de Lancie suggested that Strauss compose an oboe concerto. ${ }^{114}$ Regrettably, de Lancie did not have the opportunity to premiere this work, but the Strauss Concerto has become one of the most important pieces of the repertoire. ${ }^{115}$ De Lancie is also responsible for the addition of L'horloge de Flore ("The Flower Clock") to the repertoire by commissioning Jean Francaix to write a solo oboe piece with orchestra. His luck was better with this concerto, for de Lancie gave the premiere in 1961 with Eugene Ormandy and the Philadelphia Orchestra. He performed the work many times, and

\footnotetext{
${ }^{111}$ Storch, Marcel Tabuteau, 201.

${ }^{112}$ Martin Anderson, “Obituary: John de Lancie,” Independent Newspapers UK Limited, May 28, 2002, http://dfinarticles.com/p/articles/mi-qu4158/is-20020528/ai-n12618510.html (accessed June 10, 2010).

113 Ibid.

${ }^{114}$ John de Lancie, "Some Thoughts on the Strauss Concerto," The Double Reed 18, no. 2 (1995): 61.

115 Ibid. Following this fortuitous encounter, de Lancie learned that Strauss began work on an oboe concerto because of "a suggestion from an American soldier...". (This is the actual inscription on the title page of the manuscript.) Strauss invited de Lancie to the world premiere, which took place in March, 1946 in Zurich. Although de Lancie was in Switzerland at the time of the invitation, he had planned to leave January, 1946 to begin his work in Pittsburgh, so he declined. Later, de Lancie was offered the opportunity to play the American premier with the Philadelphia Orchestra. However, Tabuteau would not allow his assistant and student to play the first performance, angrily asserting, "If anyone is going to play, it will be the solo oboist of the orchestra."
} 
recorded it with the RCA Victor label. Besides Francaix's work, he also commissioned Benjamin Lees, and premiered his concerto with the Philadelphia Chamber Orchestra in 1964. In addition to commissioning new works, de Lancie performed pieces beyond the standard repertoire. For example, he can be credited with bringing Bohuslav Martinůs Oboe Concerto (1955) out of obscurity. De Lancie can be heard on numerous recordings with the Philadelphia Orchestra. He also made several solo recordings. Additionally, as one of the founding members of the famed Philadelphia Woodwind Quintet, de Lancie played oboe for twelve of the most well-known quintet recordings. Thus, his tireless efforts of performing and recording gained him worldwide recognition, which prompted the "Philadelphia style" to flourish.

De Lancie's numerous recordings have left a permanent record of his oboe playing. As Richard Woodhams, his successor in the Philadelphia Orchestra, stated about the group's recordings, "You could immediately recognize it was the Philadelphia Orchestra from his oboe playing,...It was sort of bright and dark at the same time, and had a kind of suppleness to it." In terms of technique, Woodhams claimed, "Mr. de Lancie had a formidable and what I think of as 'Chopinesque' finger technique. He used very little motion and a light touch so that the fastest passages came out cleanly and elegantly without any mechanical clatter whatsoever." McGill asserts that de Lancie's recording of L'horloge de Flore "captures the best of de Lancie's playing." He performed the work with "metrical, tonal, and articulative precision," a style of playing that John Minsker declared "not only kept the standard the Tabuteau had set in that Philadelphia Orchestra but that he also built [sic] upon it." ${ }^{\prime 16}$

This level of perfection on the oboe was achieved through the comprehensive instruction he received from Tabuteau. When he became a teacher, de Lancie continued to build upon the fundamental concepts concerning tone production and phrasing that he learned from his mentor.

\footnotetext{
${ }^{116}$ McGill, Sound in Motion, 326.
} 
The first crucial aspect of his pedagogy concerns curriculum. Like Tabuteau, de Lancie emphatically maintained that a proper foundation must be built using the fundamentals: long tones, scales, broken thirds, intervals, and arpeggios. These skills were then applied to etudes, particularly the Barret, Brod, and Ferling studies. He believed that with enough patience one can teach a student to be a first-class player using only these exercises. To attest to this fact, Woodhams revealed that when he was a Curtis student with de Lancie, his curriculum consisted solely of etudes, long tones, slow scales, and arpeggios. The only solo repertoire that was covered was for the annual oboe recital in which each student performed one or two works. ${ }^{117}$

In de Lancie's view, the ability to produce a long tone with control is crucial because long tones, especially in the low register, establish good breathing and support along with control of the whole dynamic range. ${ }^{118}$ Long tone exercises were an essential aspect of de Lancie's teaching. As Light claims, "It is my understanding that they came from Marcel Tabuteau and that most of Tabuteau's students who became well-known teachers all employed them, too. Certainly, every student who came into contact with John de Lancie spent much time and effort on them." ${ }^{119}$ Woodhams recalled how humbling it was in his first lesson with de Lancie because he began the lesson with a long tone on a low D natural. De Lancie first demonstrated by producing a tone of "seemingly endless duration that began with a clearly enunciated whisper, developed into a deep, sonorous fortissimo with no distortion of tone quality, and then gradually diminished in a perfectly modulated way so that the actual ending of the note was virtually inaudible." 120

\footnotetext{
${ }^{117}$ Richard Woodhams, “A Tribute to my Teacher: John de Lancie,” The Double Reed 21, no. 2 (1998): 81-82.

118 Jay Light, Essays for Oboists, 197.

119 Ibid.

${ }^{120}$ Woodhams, “A Tribute to My Teacher,” 81.
} 
According to de Lancie, long tones exercises should begin and end as softly as possible. Sometimes numbers were used to scale the dynamics: one equals the softest, nine, the loudest (Figure 4). ${ }^{121}$ He believed the attack should be as clean and inaudible as possible. Similarly, the note should end gracefully. De Lancie likened the attack to a "hot knife going into butter" and the release to "smoke rising in the air." 122 To produce a proper long tone, de Lancie emphatically emphasized, the pitch must remain constant and the sound should not waver. The dynamic must always be active, either in the crescendo or decrescendo. Thinking of numbers and setting the metronome to a pulse of 60 helped him to articulate this feat. The height of the crescendo would need to be as loud as possible without forcing the sound. No vibrato would be used unless it naturally appeared at the height of the crescendo. ${ }^{123}$ To accomplish these requirements, he demanded that his students develop a "prolonged sostenuto" with the air and have a responsive, flexible, and vibrant reed. ${ }^{124}$ They were also required to learn how to budget the dynamics so that the contour was clear and the crescendo and decrescendo were equally scaled. ${ }^{125}$

Figure 4. Long Tone Exercise

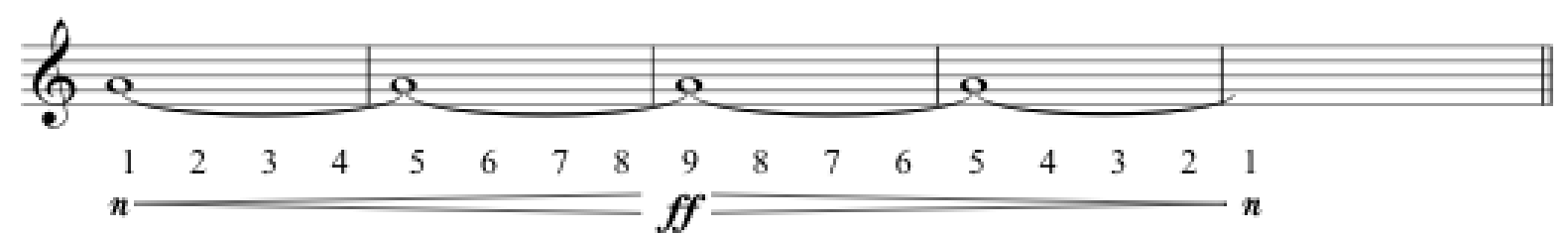

De Lancie advanced the idea that long tones are necessary for developing control of the instrument. He recognized that control of the tone could be attained by working from the soft end of the dynamic spectrum upwards. He found that inexperienced and unrefined players often strive to play loud, but the unfocused, spread tone that resulted was not the same as a full,

\footnotetext{
${ }^{121}$ Light, Essays for Oboists, 197.

${ }^{122}$ Martin Schuring, "A Daily Warm-up Routine for Oboe," ASU Studio Homepage, http://www.public.asu.edu/schuring/main.html (accessed June 4, 2010).

${ }^{123}$ Schuring, "A Daily Warm-up Routine"

${ }^{124}$ Woodhams, "A Tribute to my Teacher, " 82.

${ }^{125}$ Light, Essays for Oboists, 197.
} 
resonant, and round sound. The latter can be thought of as an "amplification of a soft, dolce tone." ${ }^{126} \mathrm{He}$ believed that it is acceptable for a young oboist to play softer for a couple of years as the dynamic range increases through long tone practice. For him, the essential matter is that the player maintains a dolce, centered tone with depth. ${ }^{127}$

For his students, variations of the long tone followed. One variation he introduced is to articulate the single tone on each pulse. This exercise develops the ability to tongue notes "on the wind." To explore this practice, one should blow the air exactly the same as the long tone. The oboist must articulate without deforming the embouchure or interrupting the abdominal support. Like Tabuteau, de Lancie used the analogy of string bowing to convey the concept of "putting the notes on the wind, not the wind on the notes." 128 The following exercise develops the ability to group notes with the proper musical inflection. One must keep the music moving forward, across the beats and the bar lines (Figure 5).

\section{Figure 5. Articulated Long Tone Exercise}

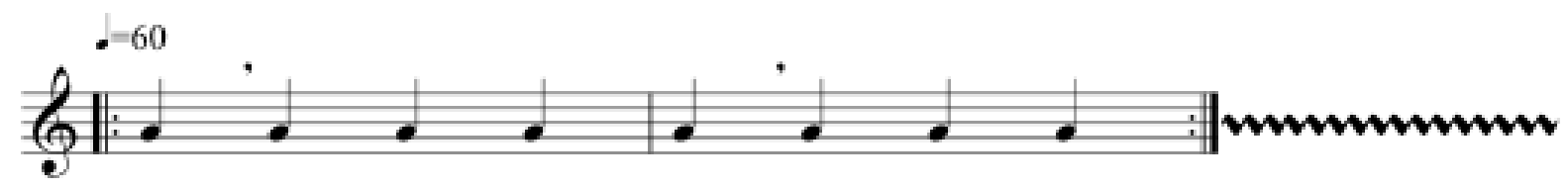

Grouping the notes in this manner corrects the habit of overly enunciating the downbeat. Each note has its own life and the music has forward motion. Additionally, de Lancie used this exercise to show that liveliness is determined by the clarity of the attack, not by the shortness of the note. ${ }^{129}$

Another variation of the basic long tone exercise as developed by de Lancie's studio relates to the practice of intervals. In the de Lancie method, the wider the interval, the more

\footnotetext{
${ }^{126}$ Woodhams, "A Tribute to my Teacher," 84.

${ }^{127} \mathrm{McGill}$, Sound in Motion, 168.

${ }^{128}$ Woodhams, "A Tribute to my Teacher," 82.

${ }^{129}$ Ibid.
} 
advanced the drill. Light illustrates an example of an interval exercise in which the oboist starts pianissimo on low $\mathrm{D}$, crescendos, slurs up a ninth to middle $\mathrm{E}$ at the peak of the fortissimo, and then returns to $\mathrm{D}$ by gently re-attacking the note and holding to niete. ${ }^{130}$ Again, the dynamics are scaled with numbers (Figure 6). The player must keep the embouchure open enough for the last note to sound on the re-attack. Furthermore, the reed must be responsive.

\section{Figure 6. Long Tone Exercise with Intervals}

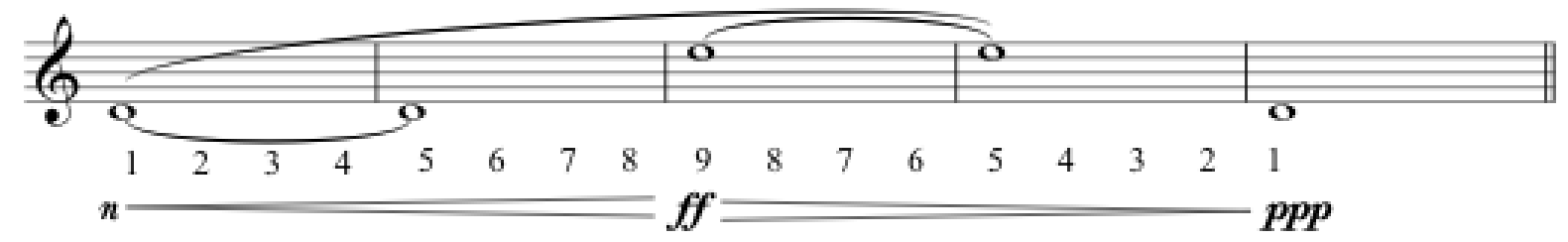

It was de Lancie's contention that practicing the fundamentals develops the correct embouchure, proper use of the air support and compels the oboist to construct stable, responsive reeds. Provided this criterion is in place, a natural vibrato will occur. In fact, when de Lancie asked Tabuteau how to produce vibrato, he replied, "Play long tones and it will happen." 131 Schuring likes to approach the topic of vibrato in the same way with his students, although he uses an exercise to generate a sympathetic vibrato for the situations when it does not come as naturally. The metronome is set to a 60 pulse. A tone is sustained to begin, and then the player adds abdominal thrusts to each pulse. Each thrust is quick and firm. As the thrusts become consistent, two are added per pulse. The number increases until five. As the thrusts get quicker, they become smoother and less aggressive, and they are felt higher in the body somewhere near the base of the neck and top of the chest. This is the point where the pulsations become a sympathetic vibrato. This vibrato is natural and the oboist can learn to refine and control its

\footnotetext{
${ }^{130}$ Light, Essays for Oboists, 201.

131 John de Lancie, masterclass (June 18, 1974).
} 
use. ${ }^{132}$ This exercise is useful in creating the natural vibrato advocated by Tabuteau and de Lancie.

Because the execution of a beautiful line was the most essential part of performance to de Lancie, he did not want any distortions. He warned students not to cover the line with a distasteful use of vibrato which, unfortunately, is used by even professional performers. It is not the main component of the oboe sound, but rather a decoration used for expressive purposes. One should only add vibrato after the "basic tone and phrase are beautiful." 133 The player should also take caution to eschew using vibrato as a cover for lack of intensity in the sound. ${ }^{134}$

Scale study was also an essential part of de Lancie's pedagogy. Scales needed to be practiced slowly, with each note connected by the wind. He urged his students to "play between the notes" so that each note was linked and matched in timbre. As the player ascended the scale, the intensity had to increase to compensate for the natural tendency of the instrument to be weak in the higher register. ${ }^{135}$ De Lancie also included other fundamental scales studies, such as scales in broken thirds and arpeggio exercises. He maintained that these exercises were crucial in developing technical proficiency on the instrument. Music is filled with these basic patterns. Therefore, the mastery of the patterns plays a key role in sight-reading, a skill that is vital as an elite performer. ${ }^{136}$

De Lancie also declared that these fundamental studies must begin as early as possible, since performance technique is dependent upon physical dexterity. He determined that achieving "impeccable coordination between the mind and fingers" ${ }^{137}$ is much easier when a person is

\footnotetext{
${ }^{132}$ Schuring, "Vibrato," ASU Oboe Studio Homepage.

133 Ibid.

134 Ibid.

${ }^{135}$ Woodhams, "A Tribute to my Teacher," 82.

${ }^{136}$ John de Lancie, "John de Lancie Addresses the International Double Reed Society at Columbus," The Double Reed 2, no. 3 (1979) http://idrs.colorado.edu/Publications/DR/DR2.3/john.html (accessed May 30, 2010).

${ }^{137}$ John de Lancie, "John de Lancie Addresses the International Double Reed Society at Columbus."
} 
young. It is generally understood that in the discipline of music, although one's intellect continues to develop throughout a lifetime, technical abilities are more difficult to achieve later in life. ${ }^{138}$

Besides the fundamentals, de Lancie focused on the etudes of Barret, Brod, and Ferling to "foster a progressive and enlightened development, both technically and musically, for the complete education of the young oboist." ${ }^{" 139}$ In his teaching, de Lancie systematically guided the students through each book in the order listed above. In his experience, it took three to four years for a student to progress through the etudes. ${ }^{140}$ Moreover, he always made his students transpose the etudes, which (like solfége) develops technique and intonation. Transposition also places demands on the student's concentration and commitment to mastering the instrument. ${ }^{141}$

These etudes encompass a wide range of musical ideas. The nineteenth-century oboists who composed them were active from the period of Beethoven to Brahms. Their etudes place the same demands on the oboist as any challenge they would have to face in the orchestra. For instance, the solo in the second movement of the Brahms Violin Concerto is a pinnacle excerpt in the repertoire. It is a daunting task to play this solo, and is intimidating to oboists of any level. However, many of the etudes in the Barret Method are more difficult in terms of breath support, breadth of interval, and phrasing. So, like Tabuteau, de Lancie believed that a perceptive student who masters the musical "problems" presented in each etude of these method books would apply them to the repertoire. ${ }^{142}$ Richard Woodhams' career is a testament to this notion, for he is one of the best orchestral and solo oboists in the United States and claims that he never played a

\footnotetext{
${ }^{138}$ John de Lancie, "John de Lancie Addresses the International Double Reed Society at Columbus."

${ }^{139}$ John de Lancie, Forward to Marylin Zupnick's “A Complete Guide to Classic Oboe Etudes,” DLM Records 0688CD-0049, 1998

${ }^{140}$ Ibid.

${ }^{141}$ Woodhams, "A Tribute to my Teacher," 83.

${ }^{142}$ Ibid.
} 
concerto or an orchestral excerpt for his teacher, John de Lancie. ${ }^{143}$ Woodhams has outspokenly considered the positive results of having not played excerpts for his teacher. He possesses the necessary tools to play the repertoire, but he also has the freedom to make his own educated musical decisions rather than following someone else's interpretation. ${ }^{144}$

De Lancie used etudes to teach musical expression. He characterized phrasing as follows: "Phrasing is the art of defining — while playing — the grammatical structure of the music." 145 Just as sentences are composed of words, a phrase is a collection of note groupings. The art of phrasing depends on the player's ability to relate the notes to one another in logical groupings and then to decide upon the relative intensity of the individual notes. In his woodwind classes, de Lancie often used the example of speech by reciting the same sentence in various ways and altering the inflections. By stressing different words, meaning of the statement was altered. He illustrated this point to argue that it is the job of the performer to make the narrative clear to the listener. ${ }^{146}$ De Lancie often used the Tabuteau number system to illustrate how the phrase must move, develop and connect the notes of the line. He also showed the student how the harmonic changes relate to the movement of a phrase. Woodhams felt that de Lancie's art of phrasing was more refined and delivered more meaning to the listener than the "common approaches of a declamatory style of expression, or simply unacceptable monotone devoid of musical meaning." 147

De Lancie understood the power of intellectualizing the music. He believed that when one acquires a complete mental picture of the way the music should sound, the result will be an inspiring performance. Every note should be prepared in terms of inflection and its place in the

\footnotetext{
${ }^{143}$ Woodhams, "A Tribute to my Teacher," 83.

144 Ibid.

${ }^{145}$ McGill, Sound in Motion, 131.

${ }^{146}$ Ibid.

${ }^{147}$ Woodhams, "A Tribute to my Teacher," 82-82.
} 
phrase. Musical phrasing should be practiced consistently for a reliable performance result. He often quoted Tabuteau when he said, "You lose 50 percent when you perform; therefore, when you go on stage you have to be 150 percent prepared." ${ }^{148}$ In the performance, the player must constantly listen objectively, concentrating on the motion of the music, not the body. For this reason, he abhorred excessive bodily movement in performance.

While de Lancie addressed the topic of reed production, he did not spend a lot of time on reeds with the student. He felt that mastering the fundamentals of playing is the best guide to reed making. ${ }^{149}$ Zupnick adds that one benefit of practice in a slow and methodical way is that the control gained will generate a demand for better reeds. Although de Lancie did not become directly involved with reeds in lessons, two of his students, Jay Light and David Weber, have published two of the most widely regarded reed manuals in the United States. ${ }^{150}$ These manuals share similar principles. The goal is to make reeds with predictable standards. Reeds should be responsive, stable, and possess the basic tone quality that the player is seeking. They should speak softly and have dynamic flexibility. That way, the oboist is able to build the tone from the bottom, softer dynamic level. The reed should allow tone production with minimal embouchure bite. These are the basic building blocks. From here, the oboist will be able to adapt a reed to the particular needs of a specific playing situation. Both Weber and Light guide the reed maker to create the reed from the tip down. The tip of the reed must vibrate first. Making the reed in this way ensures that the reed will be properly balanced, for it is difficult consistently to balance reeds when the sections are made at the same time. Finally, the player should always pick a reed

\footnotetext{
${ }^{148}$ McGill, Sound in Motion, 275.

${ }^{149}$ De Lancie, Forward to "A Complete Guide."

${ }^{150}$ David Weber, Reed Making Manual and Jay Light, The Oboe Reed Book.
} 
that is comfortable to play. Often, oboists attempt to play on reeds that are too resistant. While they may sound "dark," they do not allow the player to carry the line. ${ }^{151}$

As his teaching career progressed, de Lancie became increasingly disillusioned with academia. He felt that the performance requirements placed upon students each semester in terms of recitals and number of compositions studied did not allow for his methodical approach through the fundamentals and etudes. ${ }^{152} \mathrm{He}$ observed that the trend toward producing a greater number of players has led to a general lowering of standards in the American collegiate system. Support for this view may be found by the number of performers and students in the U.S. lacking the most fundamental skills, such as the production of an acceptable long tone. Listeners, conductors, critics, and administrations have come to accept lower levels of performance as adequate. De Lancie strove for quality control. ${ }^{153}$ Eventually his insistence upon high standards and refusal to compromise led to animosity between himself and the administration of the Curtis Institute. This acrimony led to his eventual resignation. His departure from the New World School happened under similar circumstances. ${ }^{154}$

As Tabuteau's successor in the Philadelphia Orchestra and the Curtis Institute of Music, John de Lancie became one of the most significant contributors to the American school. De Lancie's high standards are evident in both his playing and the success of his students. His ideas concerning musical phrasing influenced oboists and other instrumentalists who were fortunate enough to work with him. As McGill expressed about his experiences with de Lancie, "By virtue of his woodwind classes at Curtis, he is my Tabuteau." ${ }^{155}$

\footnotetext{
${ }^{151}$ David Weber, Reed Making Manual and Jay Light, The Oboe Reed Book.

152 Stevens, "Marcel Tabuteau," 35.

${ }^{153}$ De Lancie, "Addresses the International Double Reed Society."

${ }^{154}$ Dobrin, "Obituary: John de Lancie, 80; Oboist in the Philadelphia Orchestra," The Double Reed 25, no. 2 (2002): 15.

${ }^{155}$ McGill, Sound in Motion, 325.
} 


\section{CHAPTER 5: JOHN MACK}

During his last years at The Curtis Institute of Music (1946-1954), Marcel Tabuteau's oboe studio and chamber classes underwent what is largely considered to be a renaissance. ${ }^{156}$ John Mack, who subsequently became one of the most influential oboists in the United States, was among this later generation of Tabuteau students, which also included Mark Lifschey, Alfred Genovese, Louis Rosenblatt, and Laurence Thorstenberg, all of whom went on to fill oboe and English horn positions in the top American orchestras.

Mack's success as a pedagogue during his long tenure at the Cleveland Institute of Music rivals that of his teacher, Tabuteau. Passionately dedicated, he understood and respected the great responsibility of teaching music. He was an effective communicator of both musical ideas and technical aspects of playing. Mack's students continue to hold prominent positions in American orchestras and music schools.

John Wilfred Mack (1927-2006) was born on October 30 in Somerville, New Jersey, where his father was a Presbyterian minister. Raised in Somerville, Mack's initial musical training was in piano and violin. In the sixth grade, he switched to oboe, studying with Bruno Lebate by the time he reached high school. In the twelfth grade (1944-1945) Mack began private lessons with Marcel Tabuteau. ${ }^{157}$ Every other Saturday, Mack took a train to Philadelphia for his lesson. Because his lessons were from 1-2 and his train did not leave until 6:30 pm, Tabuteau would let him stay in his studio while he gave lessons to other students. The young pupil had the

\footnotetext{
${ }^{156}$ Laila Storch, Marcel Tabuteau: 393. Storch recognizes two reasons why this renaissance occurred. The first reason is that the students whose careers were interrupted by the war had returned home; the second reason was Tabuteau's increased work with string players.

${ }^{157}$ Stevens, "Marcel Tabuteau," 83. When Mack's father approached Tabuteau requesting lessons for his son, Tabuteau told him, "Tell the boy not to play the oboe," to which Mack's father replied, "I'm sorry maestro, you will have to tell him yourself because he wouldn't take that from me." This response was enough for Tabuteau to accept Mack as his student.
} 
rare opportunity of observing the master at work, and this arrangement reveals the special relationship that developed between Mack and Tabuteau. Mack possessed a combination of talent, intelligence, and stubbornness that intrigued Tabuteau and it was for this reason that Tabuteau afforded him opportunities not offered to his other students.

At that age, Mack knew he had great potential, but was unable to access it completely. He also claimed later that he had been in awe of Tabuteau, to the extent that he did not remember much from his initial year of study. Nonetheless, he certainly absorbed a great deal in the atmosphere of Tabuteau's studio.

Following that year, Mack attended the Juilliard School, where he remained for three years. During his first year, he studied with John Minsker, the English horn player of the Philadelphia Orchestra. Minsker was somewhat uncomfortable with the situation because Tabuteau would scold Minsker whenever Mack "did a stupid thing, which I did all the time." 158 Expecting to be drafted, Mack began his study at Juilliard as a part-time student. Because he had attended Juilliard's summer school several times, and also had perfect pitch, he was able easily to pass out of dictation and to skip many fundamental requirements. When he was not drafted, he approached Edgar Schenkman, Juilliard's orchestra director, and auditioned for a place in the ensemble. Mack was appointed principal oboe at the age of eighteen and also became a founding member of the New York Woodwind Quintet.

In Mack's last year at Juilliard, Harold Gomberg, principal oboist of the New York Philharmonic Orchestra, began teaching oboe at the school. At the time, there were thirty-one oboists at Juilliard, the large number due to students taking advantage of the GI Bill. Out of the twelve people that auditioned for Gomberg, Mack was one of four accepted into his studio.

\footnotetext{
${ }^{158}$ Stevens, "Marcel Tabuteau," 84.
} 
Upon his departure from Juilliard, Mack had a standing invitation from Tabuteau to study with him again at the Curtis School. Although Gomberg encouraged Mack to go out and play auditions, Mack did not feel ready. Tabuteau agreed with him, and accepted him into his studio at Curtis. ${ }^{159}$

During the three years that Mack studied at Curtis, he participated in the wind classes coached by Tabuteau. ${ }^{160}$ The wind classes offered included a beginning and senior level. In his first year, Mack played in both groups. These groups included Louis Rosenblatt, Walter Bianchi, and Larry Thorstenberg. Rosenblatt and Bianchi were new students, while Thorstenberg was a more advanced student. While coachings were intense, Mack claimed they were also fun, as Tabuteau would blend humor into his important lessons. In fact, many non-oboists attended the classes just to take notes. ${ }^{161}$

Lessons at Curtis were usually forty-five minutes but, for oboists, they were only thirty. During these lessons, Mack played only Ferling and Barret etudes. Since solo recitals were not required as part of the curriculum, he did not work on solo literature. ${ }^{162}$ Tabuteau often made his students transpose these etudes to the "nearest, most difficult key." Mack incorporated this practice of transposing etudes into his own studio. He maintained that the act of transposing can "liberate ones playing by developing a familiarity with the instrument that results in the kind of freedom that jazz players enjoy." ${ }^{163}$

\footnotetext{
${ }^{159}$ Stevens, "Marcel Tabuteau," 86. Mack was Gomberg's "fair-headed boy," but when Gomberg found out about the audition with Tabuteau, he kicked him out of his studio for the last six weeks of classes. He even went as far as attempting to have him flunked during his final playing exam. Even worse, Gomberg did not speak to Mack for thirty-one years. The two men finally made peace with one another in 1979, following a Tabuteau tribute concert in which Mack performed. Gomberg approached him and "stuck out his hand and said, 'John that was absolutely magnificent. I am so proud of you.' He shook my hand and threw his arms around me."

${ }_{160}$ Storch, Marcel Tabuteau, 399.

${ }^{161}$ Stevens, "Marcel Tabuteau," 86.

${ }^{162}$ Ibid., 102.

${ }^{163}$ Ibid.
} 
According to Mack, the specific techniques that Tabuteau discussed in lessons involved primarily posture, hand position, and embouchure. In terms of breathing, Mack stated that Tabuteau did not mention much, except that one should use the soft palate as a valve. He never discussed specific issues such as circular breathing. ${ }^{164}$

Tabuteau was thorough in lessons. He had a systematic approach to teaching and Mack stated that he talked and played a lot, often demonstrating on the oboe. Maintaining Tabuteau's assertion that one should "play the way you think and not the way you feel," Mack carried this philosophy into his own music-making. Both oboists believed that one must understand the music well enough to trust it. According to Mack, "the liberation comes when you can play that passage just fine if somebody comes up and hits you on the head." 165 Many musicians concentrate on accurately preparing the technical aspects of a piece and rely on musical inspiration in performance. Tabuteau and Mack insisted on thorough musical preparation and practice so the musicianship is automatic in performance. This thorough musical preparation does not preclude spontaneous emotion to add to the performance.

Following his graduation from Curtis, Mack began his professional career as first oboist for the Sadler's Wells Ballet Orchestra during its North American tour in 1951-52. He then spent eleven seasons with the New Orleans Symphony as principal oboist and also taught briefly at Louisiana State University. After that, Mack played first oboe for two seasons (1963-65) with the National Symphony in Washington, DC. During this time, he also participated in the Marlboro Festival (Marlboro, Vermont) and the Casals Festival (Prades, France). In 1965, George Szell, long an admirer of Mack, invited him to play for the Cleveland Orchestra. Mack accepted the principal position, maintaining it for thirty-six years until his retirement in 2001.

\footnotetext{
164 Stevens, "Marcel Tabuteau," 93.

165 Ibid., 95.
} 
Mack enjoyed a long and fruitful career with the Cleveland Orchestra, where he played under the finest and most demanding conductors. With the orchestra, Mack participated in numerous world tours and recordings, helping to set the standards for the orchestra as it rose to international pre-eminence. In addition, he frequently performed as a soloist including premiering Ellen Taaffe Zwilich's oboe concerto, which was commissioned in honor of his twenty-fifth anniversary with the orchestra. In 1979, Harold C. Schonberg, classical music critic for the New York Times, named Mack as among the top three oboists in the country. ${ }^{166}$

In addition to his playing career, Mack was equally influential and active as a pedagogue, a responsibility that he regarded as "close to a sacred duty."167 Since 1965, Mack was the Chairman of Oboe Studies at the Cleveland Institute of Music. Like his teacher, Mack's influence stretched beyond oboe students, for he tirelessly mentored woodwind students. In addition to the Cleveland Institute, Mack was also on the faculties of the Julliard School and the Hartt School. He was also a faculty member of Blossom Music Festival (now Kent/Blossom) from its inception in 1968. Many of his students went on to hold major positions in American orchestras. David Zauder, personnel manager of the Cleveland Orchestra observed, "There is a student of John Mack in virtually every orchestra in the country." 168

Mack's commitment to teaching, coupled with the efforts of one of his star students, Joseph Robinson (principal oboist, New York Philharmonic, 1978-2005), resulted in the creation of the annual John Mack Oboe Camp in 1976. ${ }^{169}$ Mack taught at the camp each summer until his death in 2006. The legacy of the camp continues today with other instructors such as Frank

\footnotetext{
166 Adam Bernstein, “Obituary of John Mack; One of the Nation’s Top Oboists,” Washington Post, July 26, 2006.

${ }^{167}$ James R. Oestreich, "John Mack, Principal Oboist of His Time, Dies at 78," The New York Times, July 26, 2006, http://www.nytimes.com/2006/0-7/26/arts/music/26mack.html (accessed March 13, 2010).

168 Ibid.

${ }^{169}$ Elizabeth Camus, “John Mack Oboe Camp: The First Ten Years," The Double Reed 9, no. 1 (1986), http://idrs.colorado.edu/Publications/DR/DR9.1/DR9.1.Camus.html (accessed March 30, 2010).
} 
Rosenwein, the current principal oboist of the Cleveland Orchestra and a former Mack student. Held at Wild Acres Retreat in Little Switzerland, North Carolina, the oboe camp lasts one week. It offers oboists of every skill level the opportunity to immerse themselves in the traditional repertoire through a structured day of master classes, recitals, and reed-making workshops. The day also used to end in after-hour sessions of Mack recounting Tabuteau stories. ${ }^{170}$ One participant, Steve Secan, the principal oboist of the Columbus Symphony, summarized the experience: "What you get here is a part of an oral history that goes back to the Paris Conservatory of the 1880 's...It's really wonderful to plug into that long tradition and recharge your batteries. And at the same time, you're working with the young players who will be influential in the next century." ${ }^{171}$

Undoubtedly, John Mack understood the responsibility and significance of teaching. He believed that the "purpose of teaching itself is two-fold." 172 One purpose of the teacher is to develop the taste and ability of the student by teaching the student what they should and should not do, and enforce these principles. By rigorously enforcing these principles, students will develop discipline and learn to make demands upon themselves. He stated, "To me the difficulty is to get this discipline, this development of good taste-where a young musician learns to love fine playing and abhor poor playing in anyone-including in himself or herself-so that a natural development can take place.” ${ }^{173}$ Mack also revealed that he finds this task extremely challenging, for it is difficult to be a demanding teacher and yet not to discourage the student.

\footnotetext{
${ }^{170}$ James R. Oestreich, “At Peace in the Lonely Realm of the Oboe,” The New York Times, July 9, 1995.

${ }^{171}$ Ibid.

172 John Mack, "Effective Guidance for the Young Oboist," 25.

${ }^{173}$ Ibid.
} 
The second purpose of the teacher is to present 1) musical goals and 2) physical information necessary to facilitate and achieve these goals. ${ }^{174}$ Mack maintained that, unfortunately, a lot of teaching involves the delivery of physical information, to which the musical goals become a byproduct. On the other hand, if the teacher only presents musical goals, then it is left up to the student to physically figure out how to achieve the desired result. This style of teaching is precarious, for the student is in danger of developing bad habits; moreover, how is that student going to teach the next generation of oboists the fundamentals such as embouchure and tone production? Mack attempted to balance these goals in his studio, so that future generations might develop both aspects of playing. In his article "Effective Guidance for the Young Oboist," Mack claims,

I happen to be a student of the great Marcel Tabuteau, and his teaching, I would say, was 98\% aligned in musical directions, musical goals, similes, metaphors, all kinds of comparisons with nature, with this, with that, and this is marvelous for the development of your imagination, just marvelous. The only thing is that he left it up to the students themselves to find their own physical way to adapt themselves to this goal, and in so doing, they might be doing something in a rather strange way very often, and still getting quite a credible result. That's fine as far as that goes, but what happens to the next generation? What happens to the people that they teach? That's one of my great concerns as far as this whole subject goes. The very best information in the best possible way must be disseminated so that things can keep from becoming, what shall I say? - too polluted, one of our great concerns today. ${ }^{175}$

Tabuteau took care in guiding his students so that they become their own teachers, yet he was not concerned with their ability to pass on this knowledge to future generations. ${ }^{176}$ This attitude is evidenced by the fact that Tabuteau would not help his students with reeds. Fortunately, because he made reeds for Tabuteau, Mack did benefit from Tabuteau's insights and

\footnotetext{
${ }^{174}$ John Mack, "Effective Guidance for the Young Oboist," 26.

175 Ibid.

176 Stevens, “Marcel Tabuteau," 94.
} 
discoveries about reeds, even those Tabuteau wanted to keep secret. Even more fortunately, Mack chose to share what he learned with his own students.

Like Tabuteau, Mack maintained that an effective teacher must instruct the student in how to become his or her own teacher. ${ }^{177} \mathrm{He}$ stressed the importance of recording oneself during practice. This act develops the ability to hear oneself more objectively and clearly. Another suggestion for becoming one's own teacher is to memorize, for memorization allows one to listen while playing. Finally, students should become aware of patterns in music, through analytical thinking. By discovering the patterns without the aid of the teacher, the player can make educated choices about the phrasing on his or her own. Moreover, the oboist will recognize these patterns in other pieces of a similar style.

Mack described a desirable tone as one that has integrity: conviction to the sound. ${ }^{178}$ If a tone is too shallow, it is dull and lacks life. A good tone has depth and holds together so that it has the ability to carry the line. When a tone has the characteristics of life and depth, it projects. As a player's sound develops, it evolves from a tone that is more diffuse to one that becomes centered.

Mack differentiated between volume and projection, a distinction that many have misinterpreted. ${ }^{179}$ He observed that some players sound extremely loud when you are near them, but when that player is performing within an ensemble, they cannot be heard from the audience's perspective. He compared this phenomenon with players who do not seem to be forcing at all and yet their sound carries. Mack recalled hearing John Minsker, former English horn player of the Philadelphia Orchestra. The whole orchestra could be warming up, but when Minsker began to play, his tone would project through the wall of sound. Mack had difficulty describing in

\footnotetext{
177 Stevens, "Marcel Tabuteau," 94.

${ }_{178}$ Mack, "Effective Guidance," 29.

${ }^{179}$ Ibid.
} 
concrete terms this idea of projection, but he knew to play to a certain place in the hall, and he could feel himself projecting. This projection is possible only when the tone itself has depth and center.

In terms of breathing, Mack recognized that while some educators thought it adequate to advise their students simply to take a breath and blow, this guidance is often not enough. ${ }^{180}$ Mack also disagreed with the instructional advice to "breathe from the diaphragm" for it inhibits control of the wind and muscles, resulting in a locked ribcage. He preferred the phrase "breathe from the bottom." In addition, while one regulates control of the air with the abdominal muscles, Mack recognized that air may be compressed within the mouth as well. For example, compressing the air inside the mouth with the tongue results in a louder dynamic. Therefore, he did not rely only on the abdominal muscles to control the wind, but compression of air within the mouth as well. This distinction is important in creating a more relaxed state of playing.

Mack placed much emphasis on the shape of the inside of the mouth and its importance to the overall pitch, tone quality, and depth of the sound. ${ }^{181}$ By maintaining the same embouchure and forming different vowel sounds, the player can achieve various colors on one pitch. This idea is quite similar to a vocalist's approach. Unlike Bloom who emphasized the importance of an "open throat," Mack regarded this as a misconception. He maintained that the concept of the "open throat" is acceptable, especially if it prevents a student from playing in a choking position but, in actuality, it is fine to be relatively closed in the back of the throat. Essentially, the shape of the mouth affects the sound more than the relative openness of the throat. Mack directed air to

\footnotetext{
${ }^{180}$ Mack, "Effective Guidance," 29. Although he does not explicitly say which teachers, it is possible that he is referring to John de Lancie. In de Lancie's interview with Melissa Stevens, he disparagingly remarked that oboe teachers exert too much effort on describing how to breathe. From my experience, I happen to agree with Mack. Some students do need more advice on the subject.

${ }^{181}$ Ibid., 32.
} 
the bridge of his nose as opposed to down through the reed. This approach, directly related to the shape of the mouth, results in a more focused sound. ${ }^{182}$

The inside shape of the mouth's influence upon tone, both in color and dynamics, correlates with the embouchure. Mack insisted that the oboe be played with the mouth open. Otherwise, the soft palate will not be able to change "subjectively, subconsciously" to create the tone that one is seeking. ${ }^{183}$ In other words, if the embouchure is too tight, then it is impossible to alter the inside shape of the mouth. The reed is held by the lips and not lip-covered teeth. Although the player might feel stronger having more of the lips rolled inside the mouth, there is actually less control this way. More control of nuance is achieved by playing on the red part of the lips. One must search for balance, for if too much lip is on the reed, then a noisy reed with a lower pitch must be used to compensate; however, not enough lip on the reed causes the pitch to rise. ${ }^{184}$

Many oboists describe the embouchure as round, thus surrounding the reed. Mack disagreed with this concept, and preferred to think of the embouchure as "top to bottom." 185 In addition, Mack observed that there is less control if equal pressure is used with each lip. Rather, there should be a difference in pressure between the upper and lower lips. Most oboists orient to the lower lip. The chin points down, as if in the act of whistling, but without the lower lip becoming too rigid.

Mack also addressed register on the oboe and its direct relationship to embouchure. ${ }^{186}$ First, there are three obvious registers: $\mathrm{B}^{\mathrm{b} 3}-\mathrm{C}^{5}, \mathrm{C}^{\# 5}-\mathrm{C}^{6}$, and the harmonics. In addition, there are three registers that Mack recognized to be superimposed upon the first set. Those registers are

\footnotetext{
${ }^{182}$ Mack, "Effective Guidance," 29.

${ }^{183}$ Ibid., 33.

${ }^{184}$ Ibid.

${ }^{185}$ Ibid.

${ }^{186}$ Ibid.
} 
low $\left(G^{4}\right.$ and Down), middle $\left(G^{\# 4}-G^{\# 5}\right)$, and high ( $A^{5}$ and up). These superimposed registers each have a unique embouchure position on the reed. The low register is played on the tip of the reed, the middle register a median position and, with the high register; more reed is taken in progressively. However, because these registers are superimposed upon the first, they are affected by the first set in regard to closed and opened keys. When the player changes the amount of reed that is in the mouth depending on the register, the lips must roll in with the reed. Thus, the relationship between the reed and the lips remains the same, regardless of how much reed is in the mouth. Mack believed that this notion of playing on different parts of the reed according to register is crucial to the student's development of a good tonal concept.

Mack maintained that clear articulation-that is, clear attacks-results in better tone ${ }^{187}$ Like Tabuteau, Mack insisted that attacks produced by saying "tee" or "tah" are more efficient than "pah" or "hah." While some oboists are taught to begin blowing before the initial attack, Mack felt this to be problematic for younger players. Rather, he thought the oboist should learn the sequence of forming the embouchure, adding air pressure, and removing the tongue. This concept is important because the lips and the wind speed differ depending on the register and dynamic level of a given note.

When Mack discussed articulation, he also believed firmly in tonguing "on the wind," a concept that is fundamental to the American School. ${ }^{188}$ This idea of tonguing "on the wind" concerns mixed articulations, that is, when one must tongue notes of various lengths within a phrase. To achieve good tone, the oboist must not interrupt the air, stopping notes in a "passive fashion." Rather, the player must allow the tongue to come back to the reed with the wind. It is

\footnotetext{
${ }^{187}$ Mack, "Effective Guidance," 34.

${ }^{188}$ Ibid., 35.
} 
as if one were playing legato, but with articulation. Tonguing "on the wind" is possible, and desirable, regardless of the kind of articulation.

The reed has a direct effect on the ideal embouchure described by Mack, for in order to play with the mouth open (as opposed to a biting position) the reed must be made in a way that "holds up." ${ }^{189}$ If the reed is unstable, then the embouchure must undesirably compensate for the reed's inadequacies. Conversely, if an oboist plays with a bite, then he/she is probably making reeds a bit under pitch to play in tune. The ideal situation is then for a player to use an open embouchure and make reeds that accommodate such an embouchure. With this kind of reed, the oboist is searching for balance between pitch stability and depth of tone. To illustrate this point, Mack used an image of a sailboat. He stated that one is

trying to make a reed that holds itself up and won't sink, and yet resists any inclination to float away. It could be likened to a sailboat-it floats but we don't want it to be on top of every wave so it must have a keel to help it ride down in the water a little bit, so that you have more stability and more control. Elements of holding up and elements of depthlife and depth-and right in that overlapping millimeter, that's where we want our reed to be, right sandwiched in there so it's stable. ${ }^{190}$

Although the reed must be stable, it should still be flexible. This concept is one that Mack retained from Tabuteau. Mack was not referring to pitch flexibility, rather, a reed that allows the embouchure to roll in and out to accommodate the various registers of the oboe. If the reed lacks this flexibility, then the oboist will sound out of tune regardless of the quality of the instrument.

Mack made his reeds with the American "long scrape." However, he made his reeds not according to how they looked, but rather, how they played. He concentrated on the relationship between the tip of the reed and the back. Each part must function on its own, but work together. He likened this relationship to marriage, “...the tip has its own life in the reed; the back has its

\footnotetext{
${ }^{189}$ Mack, "Effective Guidance," 36.

190 Ibid.
} 
own life-but they must not act independently." ${ }^{191}$ If the tip is vibrating, but not the back, then the reed will be stuffy and lack depth. But if the two parts are not functioning autonomously, the reed will be unstable.

In 1994, Mack made a recording of orchestral excerpts with spoken commentary on how they should be performed. ${ }^{192}$ This recording provides a permanent, primary source of his teaching and approach to music-making. It is evident that Mack made intelligently guided musical decisions based on the style period, score study, underlying harmony, and his perception of the composer's intent. After each spoken commentary, it is remarkable how he plays precisely the way he discussed the excerpt. Each note has character and life, performed with a tone that is simultaneously dark and shimmery with core and resonance. Mack never uses the Tabuteau number system on this recording, but he does refer constantly to "upness and downness" 193 when describing the direction of a line. Mack frequently takes the acoustical challenges of the instrument itself into account when advising how to effectively achieve a musical goal. For instance, the oboist should use a tone that is "deep enough and dark enough" ${ }^{194}$ for the oboe solo in the first movement of Brahms Symphony No. 1. Realizing the difficulty of producing this deep, dark tone on a low $\mathrm{G}$, he offers a practical exercise for the student to try. This example is notable for it shows how Mack gave both subjective and pragmatic advice.

While Mack certainly helped propagate the Tabuteau School, he went beyond simply parroting his teacher's ideas. Rather, his intelligence and creativity led to a different way of communicating the ideas of the master. While he did give practical suggestions, he also taught using colorful analogies and advice from his own experiences. It is apparent that he stretched his

\footnotetext{
${ }^{191}$ Mack, "Effective Guidance," 36.

192 John Mack, Orchestral Excerpts for Oboe.

${ }^{193}$ Ibid.

194 Ibid.
} 
instruction beyond the traditional conservatory manner of teaching through intimidation. He was demanding and attentive to detail, but wanted his students to learn and enjoy the art of musicmaking. If a student was nervous and struggling, he would try to calm them with lighthearted suggestions such as "When in doubt in Brahms, keep the tone going. You're up against all those string players who don't like you." ${ }^{195}$ To anyone who was fortunate enough to work with Mack and experience his presence first-hand, this observation is apparent. Mack's influence upon oboe performance and pedagogy is remarkable enough that one could consider the existence of a "Cleveland (or Mack) Style" within the American School of playing.

${ }^{195}$ Oestreich, "At Peace in the Lonely Realm of the Oboe." 


\section{CHAPTER 6: REEDS}

Schools of playing are identified when oboists in a given time and place possess similar tone qualities and styles of playing. These features are related by guiding principles and methods such as aural concepts, breathing methods, embouchures, instruments, and performance milieus. All of these principles direct oboists of a given school to construct reeds according to a general pattern. Moreover, principles of tone production, reed making and phrasing are passed on from pedagogue to student. This relationship allows the ideas to propagate, thus establishing a unique "school of playing." 196

The length of the scrape ${ }^{197}$ is the primary defining feature of reed style. Throughout the schools of playing, there is a wide spectrum of scrape length. Tonal color is directly affected by the amount of cane removed from the tip, lay, heart, and back of the reed as well as how those areas are balanced. In general, reeds are categorized as having a short or a long scrape. ${ }^{198}$

Ledet recognizes five distinct international styles. ${ }^{199}$ Historically, the French style of reeds has had the most influence upon other styles. The French style is a short scrape that is used in other European styles with only slight modifications. Furthermore, what has come to be known as the American long scrape is actually a derivative of the French style. It is beyond the scope of this research to compare each style; however, it is necessary in understanding the evolution of the American style to observe that within these international styles there is generally a long scrape and a short scrape, both of which have evolved from the French reed. ${ }^{200}$

\footnotetext{
196 David Ledet, Oboe Reed Styles, 167.

${ }^{197}$ Scrape refers to the surface of exposed cane that has had layers removed by scraping with a knife. See Glossary.

${ }^{198}$ Ledet, Oboe Reed Styles, 168.

199 Ibid., 173.

200 Ibid., 185. In his study, Ledet compared the dimensions of reeds representative of all five styles and drew conclusions based upon each aspect of the reed. By comparing the length of scrape of all the reeds in the study, Ledet identified two median lengths. The median of the short scrape is 10 millimeters; the median of the long scrape
} 
General characteristics of the American style can be identified when compared with the French style. In a short scrape reed, the length of scrape is 9-13 millimeters. The long scrape reed extends the scrape to a range of 14-22 millimeters. In a short scrape reed, no bark is removed from the back. With the long scrape, the cut is extended, thus the bark is removed from the back. By scraping cane off of the back of the reed, the overall resistance of the reed is lowered, thus more wood can be left in the heart. The resistance factor, or how hard the air must be pushed against the reed, is an important aspect of tone production, for it relates to the timbre. In general, a darker sound is produced when a reed has a greater amount of resistance as a result of more cane left in the heart. A reed with less resistance generates a brighter tone.

Other dimensions are affected by the length of scrape as well. For example, in a short scrape reed, the tip and lay are longer than those of the long scrape. In addition, a long scrape reed has a shorter overall length than a short scrape reed to compensate for the flatter pitch caused by removing wood from the back of the reed. Other differences are compensated by individual methods of tone production, embouchure, and instrument.

In the first two decades of the twentieth century, Marcel Tabuteau modified the French scrape. Tabuteau's approach to reed making became known as the "American style." ${ }^{201}$ For the next thirty or forty years, Tabuteau's style proliferated throughout the United States. This proliferation occurred because the older French players in the United States retired and the younger oboists preferred the tone of the long scrape developed by Tabuteau. ${ }^{202}$ In addition,

is $18 \mathrm{~mm}$. The measurements he gathered confirm the existence of a short and a long scrape reed as two distinct categories.

${ }^{201}$ Some oboists also refer to the style as the "Philadelphia style."

${ }^{202}$ In the first half of the twentieth century, Tabuteau was not the only oboist to exert influence upon the American players. This is evident when one studies the reeds contained in David Ledet's study. For example, Alfred Barthel, former principal oboist of the Chicago Symphony Orchestra, was also a Gillet student who was "imported" to the United States. While Tabuteau modified the French scrape, Barthel did not. Known as the "Midwest Hero," he was an influential teacher, so many oboists in America contemporary with Tabuteau and his students played with a short scrape reed. Another tradition developed in California, most notably in the movie soundtrack industry of Los 
Tabuteau's students were earning positions in major symphony orchestras and propagating the style.

This chapter is a comparison of reed dimensions of eight American oboists from Ledet's study: Marcel Tabuteau, John Mack, Joseph Robinson, James Caldwell, Richard Woodhams, Robert Bloom, Robert Sprenkle, and Ray Still. ${ }^{203}$ By comparing these dimensions, variations within the American style are revealed.

The first dimension that will be considered is the thickness of the gouge. Ledet considers this measurement to be one of the most crucial because "the contour and thickness of the gouge dictates in large part the amount of cane removed proportionately from the different areas of the scrape." ${ }^{204}$ Internationally, most gouge measurements fall between .56 and .63 millimeters, with a median of $.58 \mathrm{~mm}$. Comparing these eight oboists' reeds, one notices that the range is between .53 and .63 millimeters, with a median of $.59 \mathrm{~mm}$. However, when the distribution is considered, it can be observed that many examples are thicker than $.59 \mathrm{~mm}$.

$\underline{\text { Table 1. Gouge Thickness }}^{205}$

\begin{tabular}{|l|l|l|}
\hline $\begin{array}{l}\text { Thickness } \\
\text { (to nearest.00mm) }\end{array}$ & Distribution & Oboist and Reed Reference Number \\
\hline .53 & 1 & Tabuteau (3) \\
\hline .56 & 3 & Tabuteau (1,4), Sprenkle (1) \\
\hline .58 & 6 & Tabuteau (2), Mack (2), Woodhams (1,2), Still (1,2) \\
\hline .61 & 5 & Caldwell $(1,2)$, Bloom $(1,2)$, Sprenkle (2) \\
\hline .63 & 5 & Mack $(1,2,4)$, Robinson $(1,2)$ \\
\hline
\end{tabular}

Angeles. Henri de Busscher, a Dutch oboist, is responsible for influencing a number of players in that part of the country. In general, these players used a short scrape with a wide shape and sometimes wire near the binding, which is a common characteristic of the French style reed. See Ledet, Oboe Reed Styles.

${ }^{203}$ See Appendix B.

${ }^{204}$ Ledet, Oboe Reed Styles, 185.

${ }^{205}$ In Ledet's study, only the center thickness of gouge is provided. The variable between the center of the gouge and the sides of the gouge is another important measurement to consider for it differs among individual oboists and international reed styles. This information is not made available, most likely because it would be difficult to determine on the finished reeds used for his study. 
As stated concerning international styles, the median scrape length for the long scrape reed is 18 millimeters. The twenty reeds observed in this study fall between $16.5 \mathrm{~mm}$ and 22 $\mathrm{mm}$, with the largest distribution (5 reeds) at the median of $18 \mathrm{~mm}$. Therefore, even the shortest scraped reed of $16.5 \mathrm{~mm}$. is still a long scrape in terms of international standards. In addition, these reeds average to a longer scrape of $19 \mathrm{~mm}$.

\section{Table 2. Length of Scrape}

\begin{tabular}{|l|l|l|}
\hline $\begin{array}{l}\text { Length } \\
\text { (rounded to the nearest .5 mm) }\end{array}$ & Distribution & Oboist and Reed Reference Number \\
\hline 16.5 & 1 & Woodhams (1) \\
\hline 17 & 3 & Tabuteau (1,2), Sprenkle (1) \\
\hline 18 & 5 & Mack (1,3,4),Caldwell (1),Sprenkle (2) \\
\hline 18.5 & 1 & Caldwell (2) \\
\hline 19 & 3 & Tabuteau (4), Mack (2), Woodhams (2) \\
\hline 19.5 & 1 & Robinson (2) \\
\hline 20 & 3 & Robinson (1), Bloom (1,2) \\
\hline 21 & 2 & Still (1,2) \\
\hline 22 & 1 & Tabuteau (3) \\
\hline
\end{tabular}

The width of the shape is another important contributing factor which affects the tone quality of the reed. ${ }^{206}$ The international median is 6.95 millimeters, with a majority of reeds ranging between $6.80 \mathrm{~mm}$. and $7.10 \mathrm{~mm}$. Most of the American reeds for this study are on the narrow side of the international average with the narrowest reed at $6.45 \mathrm{~mm}$. and the widest at $7.15 \mathrm{~mm}$. In the distribution of the twenty reeds, the median is $6.82 \mathrm{~mm}$, which is narrower than the international median. Moreover, nine are below the international range, eight are within the range, and only three are wider than the range. It is also notable that French reeds have an

\footnotetext{
${ }^{206}$ This measurement is taken at the widest part of the reed. Certainly the measurements along the whole shape of the reed is also meaningful, but for the purpose of this study, only the widest part is considered as a general comparison of wide versus narrow shapes.
} 
average width of $6.80 \mathrm{~mm}$. through $7.20 \mathrm{~mm}$. Therefore, the American style evolved from a slightly wider shape, becoming narrower as the length of scrape increased.

Table 3. Width of Shape

\begin{tabular}{|l|l|l|}
\hline Width & Distribution & Oboist and Reed Reference Number \\
\hline 6.45 & 1 & Mack (4) \\
\hline 6.50 & 1 & Mack (3) \\
\hline 6.60 & 1 & Woodhams (1) \\
\hline 6.62 & 1 & Bloom (1) \\
\hline 6.65 & 1 & Bloom (2) \\
\hline 6.73 & 1 & Robinson (1) \\
\hline 6.75 & 1 & Caldwell (1) \\
\hline 6.77 & 1 & Sprenkle (1) \\
\hline 6.78 & 1 & Mack (2) \\
\hline 6.80 & 2 & Mack (1), Caldwell (2) \\
\hline 6.82 & 2 & Tabuteau (3), Robinson (2) \\
\hline 6.85 & 1 & Woodhams (2) \\
\hline 6.92 & 1 & Sprenkle (2) \\
\hline 7.05 & 1 & Still (1) \\
\hline 7.10 & 1 & Tabuteau (1) \\
\hline 7.11 & 1 & Tabuteau (4) \\
\hline 7.15 & 2 & Tabuteau (2), Still (2) \\
\hline
\end{tabular}

The length of cane from the binding to the tip reveals the amount of potential vibrating mass. ${ }^{207}$ According to Ledet, all of the factors being equal, this dimension has the most influence on the pitch level. Internationally, the median of this measurement is 25 millimeters with 77.38 percent ranging between 23 and 26 millimeters. Half of the American reeds studied are within that range. Eight reeds are shorter and two are longer. In addition, the average length is 23 millimeters, two mm. shorter than the international median. Therefore, the length of cane on the American reeds is generally shorter to compensate for the lower pitch that results from the long scrape. If the length of cane is too long, the pitch will be flat.

\footnotetext{
${ }^{207}$ Ledet, Oboe Reed Styles, 194.
} 
Table 4. Length of Cane

\begin{tabular}{|l|l|l|}
\hline $\begin{array}{l}\text { Length } \\
\text { (to the nearest } .5 \mathrm{~mm} . \text { ) }\end{array}$ & Distribution & Oboist and Reed(s) Reference Number \\
\hline 21 & 1 & Tabuteau (4) \\
\hline 21.5 & 3 & Robinson (2), Caldwell (1), Woodhams (2) \\
\hline 22 & 3 & Tabuteau (3), Caldwell (2), Woodhams (1) \\
\hline 22.5 & 1 & Mack (1) \\
\hline 23 & 5 & Mack (3,4), Robinson (1), Still (1,2) \\
\hline 24 & 4 & Mack (2), Bloom (1,2), Sprenkle (1) \\
\hline 24.5 & 1 & Sprenkle (2) \\
\hline 28 & 1 & Tabuteau (1) \\
\hline 28.5 & 1 & Tabuteau (2) \\
\hline
\end{tabular}

The last measurement indicates the overall length of the reed from the bottom of the staple to the tip of the reed. This dimension affects the pitch level as well as the balance of the scale, the tone quality and the response. In this category, most of the American reeds are again shorter than the international average. The international median is between 71 and 72 millimeters, with most reeds in the range of 70 to $73 \mathrm{~mm}$. While some of the American reeds are within that range as well, most are $70 \mathrm{~mm}$. and below, with the shortest example measuring at 67 $\mathrm{mm}$. The median is $69.7 \mathrm{~mm}$, which can be rounded up to $70 \mathrm{~mm}$, but if the long Tabuteau examples are excluded as outliers, then the average is $69 \mathrm{~mm}$. 
$\underline{\text { Table 5. Overall Length }}$

\begin{tabular}{|l|l|l|}
\hline $\begin{array}{l}\text { Length } \\
\text { (to the nearest .5 mm.) }\end{array}$ & Distribution & Oboist and Reed(s) Reference Number \\
\hline 67 & 1 & Woodhams (2) \\
\hline 67.5 & 1 & Tabuteau (4) \\
\hline 68 & 4 & Caldwell (1), Woodhams (1), Still (1,2) \\
\hline 68.5 & 3 & Tabuteau (3), Robinson (2), Caldwell (2) \\
\hline 69 & 2 & Mack (3,4) \\
\hline 69.5 & 1 & Mack (1) \\
\hline 70 & 3 & Mack (2), Robinson (1), Sprenkle (1) \\
\hline 70.5 & 1 & Bloom (2) \\
\hline 71 & 1 & Bloom (1) \\
\hline 71.5 & 1 & Sprenkle (2) \\
\hline 75.5 & 1 & Tabuteau (2) \\
\hline 76 & 1 & Tabuteau (1) \\
\hline
\end{tabular}

The length of the staple is one more factor to consider. Most reeds use a staple length of 47 millimeters. The next common size is $46 \mathrm{~mm}$. These statistics apply to the American reeds as well. If a shorter staple is used, it will raise the overall pitch.

Table 6. Length of Staple

\begin{tabular}{|l|l|l|}
\hline Length & Distribution & Oboist and Reed(s) Reference Number \\
\hline 45 & 2 & Still $(1,2)$ \\
\hline 46 & 7 & Mack $(2,3,4)$, Woodhams (1,2), Sprenkle (1,2) \\
\hline 47 & 11 & $\begin{array}{l}\text { Tabuteau }(1,2,3,4), \text { Mack (1), Robinson (1,2), Caldwell }(1,2), \text { Bloom } \\
(1,2)\end{array}$ \\
\hline
\end{tabular}

Other dimensions affect the sound of a reed. For example, the thickness of the tip has a great impact on tone quality, with a majority of oboists preferring the tone quality of a thinner tip. For both international reeds as well as American reeds styles, there is a tendency toward thin and balanced tips. ${ }^{208}$ In addition, most reeds are thicker in the center of the tip than the sides.

\footnotetext{
${ }^{208}$ A tip is considered "balanced" when the same amount of cane has been removed proportionately on each side of the blade (left/right). Because there are two blades, the top and bottom blade must also match.
} 
Also, it can be observed that those oboists who have adopted the American scrape create a triangular shape in the back corners of the tip, thus the tip is cut into an inverted "V" shape. This trait is present to varying degrees in the American reeds included here.

Ledet identifies the effect on pitch when considering the assorted dimensions of a finished reed. This observation is significant, for it reveals how one dimension is compensated by another. For example, a thick gouge is associated with a flat pitch. Other factors that flatten (lower) pitch include a long scrape, wide shape, long overall length, and a long staple. Of course there are other contributing factors, but in general, the inverse is true. Therefore, a short scrape, narrow shape, short length, and a short staple will all create a higher pitch level. Where one set of dimensions occurs, such as the long scrape occurs, oboists compensate with another set of dimensions. ${ }^{209}$

Table 7. Reed Dimensions and their Effect on Pitch

\begin{tabular}{|l|l|l|}
\hline & Flatness & Sharpness \\
\hline Gouge & Thick & Thin \\
\hline Scrape & Long & Short \\
\hline Shape & Wide & Narrow \\
\hline Length of cane & Long & Short \\
\hline Overall length & Long & Short \\
\hline Staple & Long & Short \\
\hline
\end{tabular}

When the averages of the eight players' reeds studied here are considered, one can observe the following. The gouge is relatively thicker and the scrape is longer than other national styles. The American players have scraped their reeds in that manner in order to retain more wood in the heart and, by leaving more cane in the area of the heart, a darker tone is achieved. The flatness caused by these variations is compensated by the overall use of a narrower shape and slightly shorter cane and overall length. Differences within the American style are the

\footnotetext{
${ }^{209}$ Ledet, Oboe Reed Styles, 194-195.
} 
consequence of individual embouchures, musical and acoustical conditions, physical characteristics, aural conceptions, and teacher influences. Therefore, variations within the American school arise when the reeds of specific players are considered.

Of the reeds studied for this project, it is interesting to observe that Tabuteau's reeds seem to be the most inconsistent. There are several factors that could contribute to this aspect of his reeds. Tabuteau's concept of tone evolved throughout his career, which gradually developed the long scrape from the shorter French scrape. He made reeds based upon how they play and not how they appear. He believed that the gouge was more important than the scrape. He used 10.0 to 10.5 diameter tube cane that he hand-selected from the Var region of France. He preferred a gouge that measured between .57 and .59 millimeters, maintaining that a gouge below .55 millimeters is too thin to use, and above .60 millimeters too thick. In addition, he preferred to gouge the sides thinner than the center. He was very demanding about the settings, meticulously sharpening and shaping the blade by hand. ${ }^{210}$

These facts are interesting because the reeds that are included in the Ledet study possess gouges of $.56, .58, .53$, and .56 millimeters. These measurements are actually relatively thin compared to the other gouge sizes that have been studied for this paper. In addition to the somewhat thinner gouge, Tabuteau used a relatively wide shape. Three out of the four reeds have widths greater than 7 millimeters. In balancing the pitch of a reed, a wider shape can be used with a thinner gouge. These characteristics resemble the French style of reeds. What set Tabuteau's reeds apart from their French predecessors are that he lengthened the scrape. In two of the examples, the reeds are relatively short (below 69 millimeters) and the scrape extends almost completely to the binding. The other two reeds are extremely long in overall length, the longest measuring 76 millimeters. However, the scrape is only 17 millimeters with a large

\footnotetext{
${ }^{210}$ Ledet, Oboe Reed Styles, 159.
} 
amount of unscraped cane between the back and the binding. According to Ledet, these reeds were probably flat in pitch, but correct in appearance. Thus, one can conclude that Tabuteau was fairly experimental with measurements, particularly the dimensions of the gouge. ${ }^{211}$ This conclusion makes sense historically since he was responsible for evolving the French scrape into the American scrape.

Unfortunately, Ledet did not explain how he selected Tabuteau's reeds for inclusion in his study, nor did he indicate when they were made. Consequently, it is inexplicable why the measurements are so varied. Nonetheless, his use of the long scrape can be observed and information regarding his thoughts on the importance of the gouge is provided.

Including Tabuteau's reeds in this project is useful for it provides a basis for the study of those oboists that continued the tradition. Philip Kirchner, Tabuteau's first student in the United States, stated, "In my opinion, most oboists in the United States owe Tabuteau a debt of gratitude. He established our present school of oboe playing. Heretofore, there had been none. Regarding reeds, with some variation, all of Tabuteau's students use the same system of reed making - the long scrape."212

Ledet included four examples of John Mack's reeds in his study. ${ }^{213}$ The first two reeds are from 1958 and were used in concerts; the later examples are from 1979. These reeds reveal some interesting aspects of Mack's reed making that can be compared with other player's reeds. Generally, Mack preferred a heavier gouge that is thicker in the middle than the sides of the cane. To Ledet, Mack stated that he gouged his cane from .58 (center) to .45 (sides), which

\footnotetext{
${ }^{211}$ Short scrape reeds are made with a thinner gouge overall and thinner sides compared to the center of the gouge. The long scrape requires a thicker gouge, and although the sides are thinner than the middle, the proportion is less extreme. It would have been necessary for Tabuteau to experiment with various measurements in order to discover the necessary modifications of the gouge with the long scrape.

${ }^{212}$ Ledet, Oboe Reed Styles, 131-132.

${ }^{213}$ Ibid., 134-135.
} 
reveals this variance. However, there are some inconsistencies with Ledet's study because three of the four reeds that Mack provided have a gouge of .63 millimeters, the thickest of the reeds selected for this paper. While the reason for this discrepancy is unknown, it can be concluded that a gouge with this thickness would need to be compensated with a narrower shape. All four of the examples have a narrow shape, but the latter two from 1979 are narrower than the first. (The shape used for these examples was a Pfeifer shaper tip, now reproduced as the Pfeiffer/Mack \#1 tip.) Another observation about his reeds is made through physical appearance. Although all four reeds have the inverted "V" shape of the tip, the latter two have a sharper drop in the back corners of the tip. In addition, the three general areas of the reed, tip, heart, and windows are very clearly defined. Also, the measurements and appearance of his reeds are consistent. Finally, it is interesting to observe that Mack used staples shorter than the average 47 millimeters.

Joseph Robinson was a student of both Mack and Tabuteau; however, his reeds are more akin to Mack's style. Like Mack's reeds, the three sections are clearly defined and have a considerable inverted "V" shape at the tip. He constructed reeds that would not have to be compensated by embouchure and other physical means, stating: "If there is an overriding principal which has guided the evolution of American reeds, as opposed to typical European ones, it is that the reed should have built into itself the structural elements necessary to provide ease of response, richness of tone, and stability of pitch without resort to the external supports and constraints of embouchure to achieve these attributes." ${ }^{214}$ Like Mack, Robinson also preferred a relatively thicker gouge and a narrower shape. Aside from a slightly longer scrape and the use of 47 millimeter staples, the remaining measurements are similar to Mack's reeds.

\footnotetext{
${ }^{214}$ Ledet, Oboe Reed Styles, 147.
} 
Although John de Lancie did not provide reeds for the Ledet study, his approach to making reeds can be ascertained from other sources. Similar to Mack, de Lancie used an open embouchure with little bite. Therefore, stability needed to be built into the reed in order to attain a free sound with no biting. In fact, he believed that if one has an embouchure with a stronger bite, then one is likely to be less discerning about reeds. ${ }^{215}$

For de Lancie the tip must vibrate first in order to create a stable reed. In addition, he maintained that the lay between the tip and the heart is a critical area of the reed. This area is affected by the gouge and the quality of the cane. To create a darker tone, de Lancie scraped the lower corners of the tip, which creates the defined inverted "V" that is a common characteristic of the American style reeds. ${ }^{216}$

Other ideas concerning de Lancie's approach to reeds can be pieced together from outside information. For the purpose of this project, the reeds of James Caldwell and Richard Woodhams are included from the Ledet study. Caldwell and Woodhams both studied with de Lancie, and Woodhams eventually succeeded his teacher as both principal oboist of the Philadelphia Orchestra and oboe professor at the Curtis Institute. It is interesting to note that according to his biographical information, Woodhams also studied with Mack and Bloom. For this reason, his reed design could be influenced by not only de Lancie, but Bloom and Mack as well. Both Caldwell and Woodham's reeds are fairly consistent with the averages of the reeds that were studied for this paper. In addition, they exhibit many characteristics similar to the reeds of Mack and Robinson, especially in terms of the inverted "V" tip and the clearly defined sections. Also, a lot of cane is removed from the windows with "catches" 217 between the heart

\footnotetext{
215 John de Lancie, masterclass, June 1974.

216 Ibid.

${ }^{217}$ A "catch" is a buildup of cane on the reed caused by not following through with the knife stroke. Many oboists prefer to create a catch between the back of the heart and the top of the back scrape.
} 
and the top of the back scrape. Moreover, Woodhams seems to have two sections to his hearts, where more cane is removed from the back of the heart than the top of that area. One interesting dimension is the overall length. Both Caldwell and Woodhams gave examples of shorter reeds, all under 69 millimeters. Moreover, Woodhams used shorter staples, which would create very sharp reeds. Perhaps these dimensions existed to compensate for a flat oboe or a looser embouchure.

In 1980, Woodhams provided Ledet with some insightful comments about his approach to reed making. ${ }^{218} \mathrm{He}$ remarked that he tries to create reeds that have "an optimum degree of resonance" as a means to "effectively interact with the way in which I produce the sound and the acoustic environment in which I commonly play." Thus, his reed making is guided by his playing conditions and how he produces the sound in terms of embouchure and air support.

The next three oboists' reeds, those of Robert Bloom, Robert Sprenkle, and Ray Still, provide some insight into a variation of the "American scrape." The first observation that one can make is attained through visual inspection. Bloom's tips have less of an extreme "V" shape in the tip. Although there appears to be less of drop-off of the back corners of the tip into the heart, the sides and the upper of the corners of the tip are thinner than the middle. There is more shading in the center of the tip with a clear "half-moon" shape defined by the thinness of the sides and upper corners of the tip. It can also be observed that Bloom's reeds have a relatively short heart and a longer back scrape as compared to other American style reeds. Although the back scrape is long, the windows are not as thin as the other reeds discussed so far. One reed actually has "back windows," so that the back part of the back scrape is thinner than the top, where the windows are usually thinner. This is another variation of the American style because usually the windows are the thinnest part of the back scrape.

\footnotetext{
${ }^{218}$ Ledet, Oboe Reed Styles, 166.
} 
The dimensions of the reeds provided for the Ledet study are consistent. Bloom used a somewhat thicker gouge of $.61 \mathrm{~mm}$., paired with a narrower shape. Other measurements are slightly longer than the other reeds discussed in this chapter. Both of Bloom's reeds are longer than $70 \mathrm{~mm}$, and the scrape is longer as well, measuring at $20 \mathrm{~mm}$. Bloom did not provide very much information to Ledet, but he did state that the reeds he donated for the study were compatible with the ones that he played. He further added that his ideas about reeds changed over time.

The final two oboist's reeds from the Ledet book are those of Robert Sprenkle and Ray Still. Sprenkle studied with Bloom and became oboe professor at Eastman; Still considers Bloom to be the teacher that influenced his playing the most. In addition, in 1958, Still claimed that "his reeds are, in general, of the Tabuteau-Bloom school with some of the Sprenkle influence..."219 This comment suggests the diversity within the American style.

Although Sprenkle studied with Robert Bloom and was a disciple of the American school, his reeds are the most distinct of the examples studied for this paper. Visually, the scrape of the tip does not have the inverted "V" shape that is so evident in other reeds from this school. While the sides and corners of the tip are thinner, the cut of the blend area between the tip and the heart is straight, lacking the inverted "V." Although Sprenkle used a long scrape, the windows are not as defined in the back of the reed as in that of other player's. However, although the back is not as defined, the sides of the heart and back are thinner than the center. Sprenkle's style remained consistent throughout his playing career. While the pictures of his reeds in the Ledet book are from 1958, in 1979 he claimed that they are still "the same general style." ${ }^{220}$ In his comments to Ledet, he described his reeds as having "modest resistance," and he tested them

\footnotetext{
${ }^{219}$ Ledet, Oboe Reed Styles, 157.

${ }^{220}$ Ibid., 154.
} 
to be responsive and vibrant. He aimed for a $\mathrm{C}$ crow, ${ }^{221}$ but allowed for an adjustable range (from G to D) with the use of embouchure. This trait confirms that Sprenkle played with a flexible embouchure, a characteristic common to the American style of playing.

In addition to the atypical scraping style of the tip, Sprenkle's reeds also exhibit some unusual measurements. The reeds that were measured for Ledet's study reveal the use of 46 millimeter staples, which is shorter than the usual $47 \mathrm{~mm}$. The overall lengths of his reeds in the study were average, so the shorter staple most likely compensated for the pitch of his oboe or the tuning of his playing situation. However, in his 1979 comments to Ledet, he stated that he was using 45 millimeter staples with a total length of 67 to 69 millimeters. ${ }^{222}$ Both of these measurements are shorter than other reeds of the same style and would produce a higher pitch level.

Still's reeds exhibit general characteristics of the American style along with some of Sprenkle's traits. One similarity to Sprenkle's reeds is the length of his staples. His staples were shorter, measuring at 45 millimeters. In addition, his reeds finished at the relatively short length of 68 millimeters. Visually comparing Still's tip to those of Bloom and Sprenkle shows that they resemble Sprenkle's tips but with a more pronounced inverted "V." In his comments to Ledet, he explained that his shape is a copy of Bloom's, although in the Ledet study, his shape is wider than Bloom's. It is possible that Still tied his reeds at a shorter length, which would account for the wider shape. Given the short lengths of his reeds, a wider shape would help balance the pitch level. In any case, it is notable that he used a copy of Bloom's shape for it reveals that Still was influenced by Bloom's reed style.

\footnotetext{
${ }^{221}$ The "crow" of the reed is the sound that is produced when the reed is blown by itself, not in the oboe. Reed makers crow the reed away from the instrument to test how the reed is functioning during its construction. The ideal pitch of an American style reed crow is C5, produced when the reed is blown at the binding without embouchure pressure. Most reed makers can finish a reed to the point of final refinements just by testing the "crow."

${ }^{222}$ Ledet, Oboe Reed Styles, 155.
} 
Still also discussed the characteristics he looked for in a reed. One characteristic is that the reed has the customary "C-crow." In addition, he searches for the balance between a minimum of resistance and a core to the sound. He discussed the relationship between his reeds and his embouchure. He wanted to play on a reed that allowed him to hold the reed in his mouth as close to the tip as possible. He described an embouchure that is "puckered" without a strong bite; the reed should be allowed to vibrate with freedom. Finally, Still commented that he created less of an extreme drop-off between the lay and the tip of the reed, so his reeds have more of a graduation between these sections than the Tabuteau reed. This comment reinforces the idea of variations within the American style.

In the first part of the twentieth century, Marcel Tabuteau modified the French reed style by lengthening the scrape. This modification allowed Tabuteau to produce a rich and varied tone color due to the enhanced lower partials in the vibrations. It also resulted in other changes of the proportions in order to keep the reed balanced. Thus, the "American style" reed is characterized by a long scrape, thick heart and gouge, and a relatively short overall length. Due to Tabuteau's influence as a pedagogue, his students made reeds in the same general style, as evidenced in Ledet's Oboe Reed Styles. Upon further observation, one notices that variations exist in the style. These deviations exist because of individual embouchures, aural concepts, and performance situations. 


\section{CHAPTER 7: CONCLUSION}

This project examined the careers of three successful students of Marcel TabuteauRobert Bloom, John de Lancie, and John Mack-focusing on their approach to tone production, which involves such aspects as embouchure formation, vibrato, breath support, and reed making, as well as their pedagogical approaches to musical expression. The purpose of this research was to discover if diversity exists within the style and, if so, how each branch of the American School is distinct.

The style of oboe playing characterized as the "American school" developed from Marcel Tabuteau. Tabuteau, who received his formal training at the Paris Conservatory with George Gillet, evolved his characteristic French style in order to adapt to different playing conditions and demands that he first encountered in America. By lengthening the short scrape reed to add lower partials to the sound, the tone of American oboists grew to be darker, richer, and more resonant than that of other European schools.

Tabuteau's career was defined by fortuitous opportunities. For example, he was the principal oboist of the Philadelphia Orchestra when the Curtis Institute opened its doors. Because Curtis recruited the principal players of that orchestra for studio instruction, Tabuteau began his legendary role as a pedagogue. He was a true master of his art and his own playing was characterized by long lines executed with perfect nuance and tonal control that involved not only a wide dynamic range, but color shading as well. As a teacher, he created and refined a method for developing phrasing. The "Tabuteau System," a term that he himself used, involved the use of numbers and "up/down" inflections to explain how to perform a musical phrase. Therefore, the American school is not only distinguished by its method of tone production but also by a management of phrasing that emphasizes long connected lines. Because of the success of the 
Curtis Institute and Tabuteau's oboe studio, his students were hired to play in newly formed orchestras throughout America, which helped to proliferate the Tabuteau/ American school.

Without Marcel Tabuteau, the American school would not have defined itself so clearly. Another player, when afforded the same opportunities as Tabuteau, would certainly have had some impact, but Tabuteau was unique. In addition to his talent and intelligence, he possessed imagination, creativity, charisma, and perseverance. For example, since tone production is directly linked with reed style, it must have taken a great deal of experimentation and patience to develop his approach to reeds. When one set of dimensions is altered, another measurement must be adjusted or the reed will be out of balance. In general, American reed makers all share similar dimensions (within a small range), but Tabuteau had to discover these measurements for himself. His method of communicating musical ideas also shows his extraordinary abilities; a native French speaker, he was compelled to teach English-speaking students in their native tongue. He managed to explain his ideas with a high degree of success, as evidenced by his influence upon the ensuing generation of oboists, as well as performers of many other instruments.

One factor to consider when discussing the students of Tabuteau is when they studied with him. All three oboists were students at Curtis at markedly different times. Bloom was one of his earlier students, Mack one of his later. De Lancie was fortunate to succeed him in both positions when he retired. Timing is notable because Tabuteau's system evolved throughout his years of teaching. For this reason, Bloom was hardly exposed to the number system, whereas de Lancie and Mack encountered it frequently. All three oboists focused on phrase structure, note groupings, and the comparison with string bowings, but de Lancie employed the number system with the most frequency in his own teaching. Further research that included other Tabuteau 
students and focused solely on the use of the "Tabuteau System" might reveal additional evidence of the proliferation of the number system.

Playing circumstances also account for individual variation within the same general style and is another topic open to more research. Bloom, de Lancie, and Mack all played in different orchestras in various halls under an array of conductors. Over time, the greater resonance and reverberation in Severance Hall (Cleveland, OH) certainly caused Mack to slightly adjust his reed style and embouchure to a greater extent than John de Lancie, who played in the Academy of Music (Philadelphia, PA). The acoustics of the hall and musical taste of the conductor would also have had an effect on specific issues such as articulation style. Additionally, while all three players had considerable orchestra, chamber, and solo experience, Bloom spent a great deal of his career working with the Bach Aria Group. This performing environment placed different demands on his playing than his orchestral work did. Most of the repertoire performed by the large orchestras in which he played is from the romantic and late romantic period, whereas the requirements for tone production and phrasing style required of him when performing with the Bach Aria Group would not have been the same. Moreover, Bloom had more artistic freedom in the collaborative atmosphere of the Bach Aria Group.

The teaching philosophies and individual personalities were also rather diverse. John de Lancie replaced Tabuteau in both of his positions when he retired. One can conclude that he felt a certain responsibility to continue and honor the Tabuteau legacy. De Lancie was dogmatic in his use of etudes and his emphasis on the fundamentals, using a similar pedagogical approach as Tabuteau. Because of this, the "Philadelphia School" (which has become synonymous with the “American School”) continued to expand. On the other hand, Mack also propagated Tabuteau's legacy at a different institution. One can speculate that his individual personality and emphasis 
on presenting fundamental concepts in transparent ways would have caused his approach to be quite different from his teacher and the other Tabuteau disciples. Bloom's emphasis upon performance practice led him to develop yet another unique method as well, for he focused on the Baroque repertoire and the student's ability to create their own ornaments and elaborations.

However, even accounting for the diverse approaches of Tabuteau students, the same general characteristics remained similar enough that an American style is evident and identifiable, especially when contrasted with other national styles. In the eyes of the world, for example, an oboist who uses a long scrape reed is considered an America style oboist. Other factors set apart the American style. Although most American style players still prefer Lorée oboes, some oboists have begun using other brands, such as Yamaha. It is significant that Yamaha distinguishes between styles, manufacturing an American and a European bore. Because the aural conception varies between the national styles, general approaches to tone production are the same, even if slight variations occur within a style. For instance, an American style oboist holds the instrument at a closer angle to the body than a French player. Because the French players hold the instrument at a higher angle, the reed also enters the mouth at a different angle causing a more nasal tone than the American sound.

Finally, another major factor to consider and research in the future is that Tabuteau's history is not the complete history of the American school. This notion is revealed in Ledet's study because he includes American reeds apart from Tabuteau's style. Many other players were imported from Europe to play in American orchestras in the early twentieth century. One example is Henri de Busser, a Belgian oboist contemporary with Tabuteau, who exerted considerable influence in the Los Angeles area and was heard on many recordings. De Busser is significant because he was Ray Still's inspiration. Still had a long, successful career with the 
Chicago Symphony Orchestra, and is the most notable player of his generation who did not study with Tabuteau. The other principal players of his time were all Tabuteau students. Still was drawn to de Busser's singing style, and although he never studied with him directly, he did study with his disciple, Philip Memoli. Still's preference for a singing style eventually led him to Robert Bloom, but most of his earlier training was with Memoli.

It is important to consider the limitations inherent in a "school of playing." It is necessary to learn to perfect the basic, fundamental requirements of tone production within a chosen style. For Example, in today's musical environment, it is doubtful that an American orchestra would hire an oboist that sounded like a French player. However, an instrumentalist needs to be more than a mere craftsman. Creativity and individualism are still necessary to become a true artist. It is this artist who will distinguish oneself in today's competitive world. 


\section{BIBLIOGRAPHY}

Anderson, Martin. “Obituary: John de Lancie.” BNet. http://dfinarticles.com/p/articles/ mi-qu4158/is-20020528/ai-n12618510.html (accessed June 10, 2010).

Bernstein, Adam. “John Mack: One of the Nation's Top Oboists.” Washington Post. http://www.washingtonpost.com/wp_dyn/content/article/2006/07/25/AR20060725014 97_pf.html (accessed June 10, 2010).

Bloom, Robert. "The Oboe, A Musical Instrument." In Robert Bloom: The Story of a Working Musician, edited by Sara Lambert Bloom, 299-336. United States of America: Sara Lambert Bloom, 2009.

Bloom, Sara Lambert, ed. Robert Bloom: The Story of a Working Musician. United States of America: Sara Lambert Bloom, 2009.

—. "Sara Bloom on Robert Bloom—The Legacy." The Double Reed 22, no. 4 (1999): 47-51.

Burgess, Geoffrey and Bruce Haynes. The Oboe. New Haven: Yale University Press, 2004.

Camus, Elizabeth. “John Mack Oboe Camp: The First Ten Years.” The Double Reed 9, no. 1 (1986). http://idrs.colorado.edu/Publications/DR/DR9.1/DR9.1.Camus.html (accessed March 30, 2010)

De Lancie, John. "John de Lancie Addresses the International Double Reed Society at Columbus." The Double Reed 2, no. 3 (1979). http://idrs.colorado.edu/Publications/ DR/DR2.3/john.html (accessed May 30, 2010).

- Forward to A Guide to Classic Oboe Etudes, by Marylin Zupnick. DLM Records 0688-CD-0049, 1998, CD.

—. "Some Thoughts on the Strauss Concerto." The Double Reed 18, no. 2 (1995): $61-62$.

De Lerma, Dominique-Rene. "Toward a Concept of Tabuteau's Phrasing." The Instrumentalist (1974): 44-45.

Dobrin, Peter. “Obituary: John de Lancie, 80; Oboist in the Philadelphia Orchestra." The Double Reed 25, no. 2 (2002): 15.

Ewell, Terry B. “A Bassoonist's Expansions upon Marcel Tabuteau's 'Drive'.” The Journal of the International Double Reed Society 20 (July 1992): 27-30. 
Felton, J. "A Great Artist's Legacy is Often the Students he has Taught." The Double Reed 3, no. 2 (1980). http://idrs.colorado.edu/publications/DR/DR3.2/great.html (February 12, 2009).

Fink, Mark. “Interview with Ray Still.” The Double Reed 21, no. 3 (1998): 87-99.

Gould, Gordon. "Ray Still- Chicago Interview." The Double Reed 10, no. 1 (1987). http://idrs.colorado.edu/Publications/DR/DR10.1/DR10.1.Gould.html (accessed May 30, 2010).

Gruenberg, Eugene. Violin Teaching and Violin Study: Rules and Hints for Teachers and Students. New York: Carl Fischer, 1919.

Hedrick, Peter, "Some Reflections on American Oboe Playing." Woodwind World 11, no. 5 (1972).

Hefner, Donald L. "The Tradition of the Paris Conservatory School of Oboe Playing with Special Attention to the Influence of Marcel Tabuteau." Ph.D. diss., Catholic University of America, 1984.

Ledet, David A. Oboe Reed Styles: Theory and Practice. Bloomington: Indiana University Press, 1981.

Light, Jay. Essays for Oboists. Des Moines: Jay Light, 1994.

- The Oboe Reed Book: Straight-Talking Guide to Making and Understanding Oboe Reeds. Des Moines: Jay Light, 1983.

Mack, John. "Effective Guidance for the Young Oboist." The Journal of the International Double Reed Society 2 (1974): 25-37.

- Orchestral Excerpts for the Oboe. Summit Records, DCD 160, 1994, CD.

McGill, David. Sound in Motion: A Performer's Guide to Greater Expression. Bloomington and Indianapolis: Indiana University Press, 2007.

Mostovsky, Marc. “The Tabuteau System: Essay and Outline.” In Laila Storch, Marcel Tabuteau: How Do You Expect to Play the Oboe if You Can't Peal a Mushroom (Bloomington and Indianapolis: Indian University Press, 2008), 533-544.

Neal, Lana C. "The American Oboe School: Its History and Hallmarks." The Double Reed 22, no. 2 (1999): 51-56.

Oestreich, James R. "At Peace in the Lonely Realm of the Oboe." The New York Times (July 9, 1995). 
—_ "John Mack, Principal Oboist of His Times, Dies at 78." The New York Times. http://www.nytimes.com/2006/0-7/26/arts/music/26mack.html (accessed March 13, 2010).

Rapier, Wayne. "Marcel Tabuteau Tape History," In Marcel Tabuteau, Marcel Tabuteau Lessons. Boston Records, BR1017CD, 1996, CD.

Robinson, Joseph. "Oboists, Exhale Before Playing." The Double Reed 10, no. 3 (1987): $16-19$.

Schuring, Martin. "ASU Oboe Studio Homepage.” Arizona State University School of Music. http://www.public.asu.edu/ schuring/main.html (accessed June 4, 2010).

- Oboe Art and Method. New York: Oxford University Press, 2009.

Schwartz, Norman B. "Robert Bloom: The Pavoratti of the Oboe." Cranberry Isles. http://cranberryisles.com/photos/robert-bloom.html (accessed November 13, 2009).

Sprenkle, Robert and David Ledet. The Art of Oboe Playing. Princeton, NJ: Summy-Birchard Music, 1961.

Stevens, Melissa A. "Marcel Tabuteau: Pedagogical Concepts and Practices for Teaching Musical Expressiveness: An Oral Tradition (Oboe).” D.M.A. diss., The Ohio State University, 1999.

- "Follow-up to the Interview with John de Lancie." The Double Reed 25, no. 4 (2002): 61-63.

Stolper, Daniel. “A Conversation with Joseph Robinson." The Double Reed 4, no. 1 (1981). http://www.idrs.org/publications/DR/DR4.1/robinson.html (accessed January 31, 2010).

_. "A Conversation with Tom Stacy." The Double Reed 1, no. 3 (1978). http://idrs. colorado.edu/Publications/DR/DR1.3/conversation.html (accessed May 30, 2010).

Storch, Laila. Marcel Tabuteau: How Do You Expect to Play the Oboe is You Can't Peel A Mushroom?. Bloomington and Indianapolis: Indiana University Press, 2008.

"Marcel Tabuteau." To the World's Oboists 2, no. 1 (1974). http://idrs.colorado.edu/ Publications/TWOboist/TWO.V2.1/TWO.V2.1.Tabuteau.html (accessed November 13, 2009).

- Liner notes to Marcel Tabuteau, Marcel Tabuteau Lessons. Boston Records, BR1017CD, 1996, CD. 
Tabuteau, Marcel. Marcel Tabuteau Lessons. Boston Records, BR1017CD, 1996, CD. "Marcel Tabuteau of Philadelphia Orchestra Summarizes Training." Transcribed by Robert Sabin. Musical America 25 (1944): 29.

Weber, David B. and Ferald B. Capps. The Reed Maker's Video. RMV-DVD-R.

Wilson, Terry and Jeanne Lorenzo. "Oboists and their Teachers: A Genealogy Chart." The Double Reed 13, no. 1 (1990). http://idrs.colorado.edu/Publications/DR/DR13.1. Oboe.Gen1.jpeg (accessed May 30, 2006).

Woodhams, Richard. "A Tribute to my Teacher: John de Lancie.” The Double Reed 21, no. 2 (1998): 81-84.

_. "Robert Bloom, Eminent American Oboist." The Instrumentalist, xliv/4 (1989-90), $24-30$.

Zupnick, Marilyn. A Guide to Classic Oboe Etudes. DLM Records 0688-CD-0049, 1998, CD. 


\section{Appendix A: Prominent Students of Marcel Tabuteau at the Curtis Institute of Music $^{223}$}

Before 1945: Robert Bloom, Harold Gomberg, Rhadames Angelucci, Arno Mariotti, John Minsker, Harry Shulman, Paul Bauman, John de Lancie, Ralph Gomberg

After 1945: Charles Morris, William Criss, Laila Storch, Martha Scherer- Alfee, Marc Lifschey, Laurence Thorstenberg, John Mack, Louis Rosenblatt, Dominique- René de Lerma, Alfred Genovese, Felix Kraus, Donald Hefner, Richard Kanter

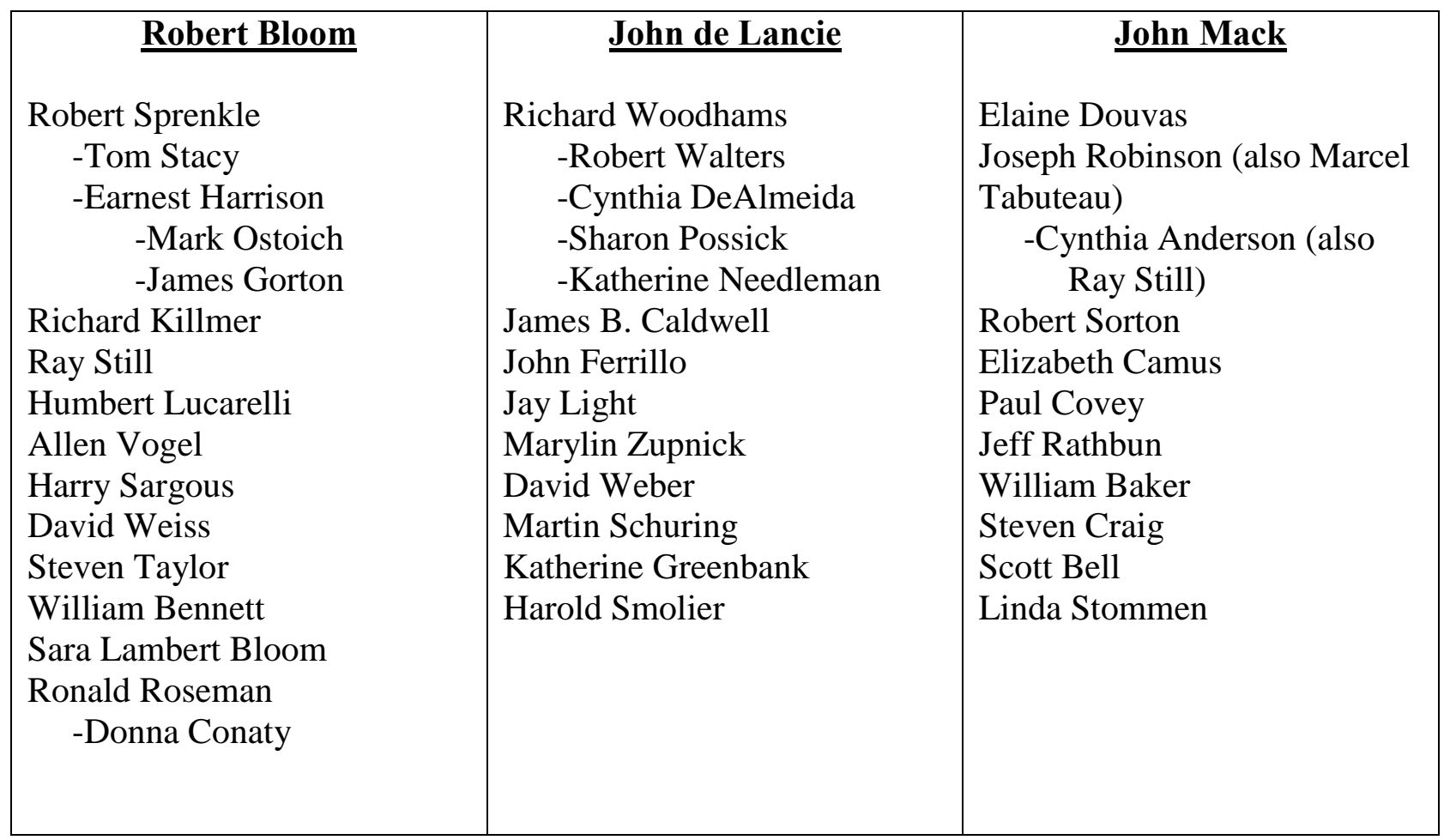

${ }^{223}$ This chart was compiled using the following sources: Storch, Marcel Tabuteau, 531-532, and Terry Wilson and Jeanne Lorenzo, "Oboists and their Teachers: A Genealogy Chart," The Double Reed 13, no. 1 (1990), http://idrs.colorado.edu/Publications/DR/DR13.1.Oboe.Gen1.jpeg (accessed May 30, 2006). 
Appendix B: Reed Dimensions of Select American Style Oboists ${ }^{224}$

\begin{tabular}{cccccccc}
\hline Oboist & $\begin{array}{c}\text { Reed } \\
\text { Number }\end{array}$ & Gouge & Scrape & Shape & $\begin{array}{c}\text { Cane } \\
\text { Length }\end{array}$ & $\begin{array}{c}\text { Overall } \\
\text { Length }\end{array}$ & $\begin{array}{c}\text { Staple } \\
\text { Size }\end{array}$ \\
\hline Tabuteau & 1 & .56 & 17.0 & 7.10 & 28.0 & 76.0 & 47 \\
& 2 & .58 & 17.0 & 7.15 & 28.5 & 75.5 & 47 \\
& 3 & .53 & 22.0 & 6.82 & 22.0 & 68.5 & 47 \\
Mack & 4 & .56 & 19.0 & 7.11 & 21.0 & 67.5 & 47 \\
& 1 & .63 & 18.0 & 6.80 & 22.5 & 69.5 & 47 \\
Robinson & 2 & .58 & 19.0 & 6.78 & 24.0 & 70.0 & 46 \\
& 3 & .63 & 18.0 & 6.50 & 23.0 & 69.0 & 46 \\
Caldwell & 1 & .63 & 18.0 & 6.45 & 23.0 & 69.0 & 46 \\
& 2 & .63 & 20.0 & 6.73 & 23.0 & 70.0 & 47 \\
Woodhams & 1 & .63 & 19.5 & 6.82 & 21.5 & 68.5 & 47 \\
& 2 & .61 & 18.0 & 6.75 & 21.5 & 68.0 & 47 \\
Bloom & 1 & .61 & 18.5 & 6.80 & 22.0 & 68.5 & 47 \\
& 2 & .58 & 16.5 & 6.60 & 22.0 & 68.0 & 46 \\
Sprenkle & 1 & .58 & 19.0 & 6.85 & 21.5 & 67.0 & 46 \\
& 2 & .61 & 20.0 & 6.62 & 24.0 & 71.0 & 47 \\
& 1 & .56 & 20.0 & 6.65 & 24.0 & 70.5 & 47 \\
& 2 & .61 & 17.0 & 6.77 & 24.0 & 70.0 & 46 \\
& 1 & .58 & 21.0 & 6.92 & 24.5 & 71.5 & 46 \\
& 2 & .58 & 21.0 & 7.15 & 23.0 & 68.0 & 45 \\
\hline
\end{tabular}

${ }^{224}$ Ledet, Oboe Reed Styles, 180-183. All measurements are calculated to the nearest millimeter, with the exception of gouge, which is rounded to the nearest 1/100 of a millimeter. 


\section{CURRICULUM VITAE}

\section{Education:}

D.M.A., West Virginia University, Oboe Performance, 2011

M.M., Cincinnati College-Conservatory of Music, Oboe Performance, 1999

B.M., summa cum laude, Ohio University, Oboe Performance, 1997

Primary Teachers: Cynthia Anderson, Dr. Mark Ostoich, Donna Conaty, Linda George-Fountain

\section{Teaching Experience:}

Lecturer in Oboe and Theory, 2009-present

Mahidol University, Bangkok, Thailand

Courses: Applied Oboe, Small Ensemble coach, Music Theory I-IV

Artist Faculty (oboe), October 1-10, 2010

SAYOWE (Southeast Asia Youth Orchestra and Wind Ensemble)

Adjunct Faculty in Oboe and Music Skills, 2008-2009

Slippery Rock University, Slippery Rock, PA

Courses: Applied Oboe, Music Skills I and II

Adjunct Faculty in Oboe, 2008-2009

Chatham University, Pittsburgh, PA

Courses: Applied Oboe

Adjunct Faculty in Oboe, 2007-2009

Frostburg State University, Frostburg, MD

Courses: Applied Oboe

Woodwinds Instructor, 2008, 2009

Chatham University Summer Music and Arts Day Camp

Courses: Elementary Woodwinds, Elementary Percussion, Woodwind Ensemble, Jazz Band, Applied Woodwinds (Flute, Clarinet, Saxophone)

Adjunct Faculty in Music Theory, 2000-2008

Chatham University, Pittsburgh, PA

Courses: Music Theory I-IV (integrated aural and written theory courses)

Graduate Assistant, 2003-2006

West Virginia University

Courses: Written Theory I-II, Aural Theory I-II

Oboe Instructor, 2003-2008

Community Music School, Morgantown, WV 
Private Oboe Instructor, 2001-2009

Pittsburgh, PA

Oboe Instructor, 2002-2003

Carnegie Mellon Summer Pre-College Program

Teaching Assistant, 2001-2003

Carnegie Mellon Preparatory School

Courses: Musicianship I-II, Music Theory

Teaching Assistant, 1999-2000

Ohio University

Courses: Sight-Singing and Dictation, Double Reeds Methods

Oboe Instructor, 1999-2000

Athens Community Music School

\section{Professional Development:}

Assistant Host, Asian Double Reed Association Conference, Bangkok, Thailand, August, 2011 Attended the Lorée Oboe Festival, Cincinnati, OH, March, 2009

Performed twice at the International Double Reed Society Conference, Ithaca, NY, June, 2007

Attended the International Double Reed Society Conference, Greensboro, NC, 2003

Attended the First International Samuel Barber Symposium, Richmond, VA, 2001

\section{Orchestral/Ensemble Engagements:}

Thailand Philharmonic Orchestra, Bangkok, Thailand, Principal Oboe (by audition), 2009present

TPO Woodwind Quintet, Bangkok, Thailand, 2011-present

Mahidol Faculty Woodwind Quintet, Bangkok, Thailand, 2010-present

Contemporary Enclave, Bangkok, Thailand, 2009-present

McKeesport Symphony Orchestra, McKeesport, PA, Principal oboe (by audition), 2004-2009

ALIA MUSICA Pittsburgh (a new music performing ensemble), Principal oboe, 2007-2009 
Performed with area orchestras including: Pittsburgh Ballet Theatre, Pittsburgh Musical Theater, Wheeling Symphony, Westmoreland Symphony, Seneca Chamber Orchestra (Charleston, WV), Opera Theater of Pittsburgh, Clarksburg Symphony, River Cities Symphony, Beaver Valley Philharmonic, The Point Chamber Orchestra, Fairmont State Orchestra, The Edgewood

Symphony, 2001-2009

West Virginia University Graduate Woodwind Quintet, Chamber Winds, Symphony Orchestra, Collegium Musicum, 2003-2006

The Poulenc! Trio (Oboe, Bassoon, and Piano), 2004-2006

Cincinnati College-Conservatory of Music Concert Orchestra, Eighteenth-Century Ensemble, Wind Symphony, Contemporary Music Ensemble, Chamber Winds, 1997-1999

Ohio University Symphony Orchestra, Wind Ensemble, 1993-1997, 1999-2000

\section{Solo Performances:}

Performed Nancy Galbraith, Reflections with Contemporary Enclave, Bangkok, Thailand, 2011

Performed Quiet City with the Thailand Philharmonic Orchestra, 2010

Faculty Recital, Mahidol University College of Music Auditorium, 2010

Doctor of Musical Arts Recitals, Bloch Performance Hall, Morgantown, WV, 2004-2010

Annual Faculty Recitals, Friday Afternoon Musicale Concert Series, Chatham University, 20012009

Performed J.S. Bach, Concerto for Oboe D'Amore with the WVU Collegium Musicum, 2005

Master's Recitals, Patricia Corbett Theater, Cincinnati, OH, 1998-1999

Performed Marcello, Concerto with the Ohio University Symphony Orchestra (Concerto Competition winner), 1997

Junior \& Senior Recitals, School of Music Recital Hall, Athens, OH, 1996-1997 


\section{Summer Festivals:}

Music09, performing participant, Blonay, Switzerland, 2009

Toured Italy with The Point Chamber Orchestra, Co-Principal Oboe/English horn, 2006

Chamber Orchestra Festival, Fairmont State University, $2^{\text {nd }}$ Oboe/English horn, 2004-2006

Lucca Opera Festival, Lucca, Italy, Co-Principal Oboe, 1998, 1999

Brevard Music Festival, Brevard, NC, student, 1996

\section{Recordings:}

Various recordings with the Thailand Philharmonic Orchestra, 2009-2011

Phantasmagorilla? No! Phantasmagoria, Efrain Amaya and The Point Chamber Orchestra, Released 2009, Albany Records

Premiere, ALIA MUSICA Pittsburgh, Released 2008, Woolslayer Travelling Studios

\section{Master Classes:}

John Mack Oboe Camp, performing participant, 2001

Performing participant in master classes given by John Mack, Marilyn Zupnick, Cynthia DeAlmeida, Kathy Greenbank, Robert Walters, and Earnest Harrison, 1997-2000

Attended master classes given by Joseph Robinson, Eric Ohlssohn, Dan Ross, Alex Klein, Jan Eberle, and Louis Rosenblatt, 1997-2009

\section{Awards and Honors:}

Pittsburgh Arts Council Grant, 2009

Graduate assistantship at West Virginia University, 2003-2006

Graduate assistantship at Ohio University, 1999-2001

Full performance scholarship, Cincinnati College-Conservatory of Music, 1997-1999

Concerto Competition winner, Ohio University, 1997 
Achievement in Performance award, Ohio University, 1997

Award for Highest Grade Point Average, Ohio University, 1995

Dean’s List, Ohio University, 1993-1997

\section{Professional Affiliations:}

International Double Reed Society

College Music Society

American Federation of Musicians

Pi Kappa Lambda National Honors Society

John H. 